\author{
RESEARCH ARTICLE \\ 10.1029/2018JC014060 \\ Key Points: \\ - The evolution of rain-induced \\ shallow stratification in a midlatitude \\ open-ocean region is highly sensitive \\ to atmospheric forcing \\ - Empirical models do not well \\ represent the observed salinity \\ anomalies \\ - A recent prognostic model for sea \\ surface salinity and temperature \\ accurately simulates rain-induced \\ salinity and temperature anomalies
}

Correspondence to:

B. Ward,

bward@nuigalway.ie

Citation:

ten Doeschate, A., Sutherland, G., Bellenger, H., Landwehr, S. Esters, L., \& Ward, B. (2019). Upper ocean response to rain observed from a vertical profiler. Journal of Geophysical Research: Oceans, 124, 3664-3681. https://doi.org/10.1029/ 2018JC014060

Received 9 APR 2018 Accepted 30 APR 2019 Accepted article online 6 MAY 2019 Published online 7 JUN 2019

(C)2019. American Geophysical Union. All Rights Reserved.

\section{Upper Ocean Response to Rain Observed From a Vertical Profiler}

\author{
A. ten Doeschate ${ }^{1,2}(\mathbb{D})$, G. Sutherland ${ }^{3}(\mathbb{D})$ H. Bellenger ${ }^{4,5}(\mathbb{D})$, S. Landwehr ${ }^{1,6}(\mathbb{D})$, L. Esters ${ }^{1,7}(\mathbb{D}$, \\ and $B$. Ward ${ }^{1}$ iD \\ ${ }^{1}$ AirSea Laboratory, School of Physics and Ryan Institute, National University of Ireland, Galway, Ireland, ${ }^{2}$ Department \\ of Oceanography, Dalhousie University, Halifax, Nova Scotia, Canada, ${ }^{3}$ Environmental Numerical Prediction Research \\ Section, Environment and Climate Change Canada, Dorval, Quebec, Canada, ${ }^{4}$ LMD-IPSL, Paris, France, ${ }^{5}$ AMSTEC, \\ Yokosuka, Japan, ${ }^{6}$ Laboratory of Atmospheric Chemistry, Paul Scherrer Institute, Villigen, Switzerland, ${ }^{7}$ Department of \\ Earth Sciences, Uppsala University, Uppsala, Sweden
}

Abstract Rainfall induces a vertical salinity gradient directly below the ocean surface, the strength and lifetime of which depend on the size of the rain event, the availability of mixing, and the air-sea heat fluxes. The presence of rain in turn influences the near-surface turbulent mixing and air-sea exchange processes. During a campaign in the midlatitude North Atlantic, the Air-Sea Interaction Profiler (ASIP) was used to investigate changes in the vertical distribution of salinity $(S)$, temperature $(T)$, and turbulent kinetic energy dissipation rate $(\epsilon)$ caused by four rain events. During one of the rain events a strong shallow stratification was formed. The buoyancy effect of this freshwater lens changes the dominant wind-driven turbulent mixing. The surface momentum flux was limited to a shallow layer, and below it $\epsilon$ is reduced by 2 orders of magnitude. For a different rain event of higher-peak rain rate, the salinity anomaly is smaller and is dispersed deeper into the water column. The difference in ocean response shows that the upper ocean is sensitive to changes in the atmospheric forcing associated with the rain events. The observed salinity anomalies as a function of rain rate and wind speed are compared to relationships from studies with the 1-D turbulence model GOTM and satellite validation. The observations suggest that the vertical salinity anomaly is best described as a function of total rain. A higher-resolution prognostic model for sea surface salinity and temperature is shown to perform well in predicting the observed $S$ and $T$ anomalies.

\section{Introduction}

Rainfall is a flux of freshwater to the ocean surface boundary layer (OSBL). Its variability directly influences the rate of exchange of heat, momentum, and mass between the ocean and the atmosphere. The OSBL is typically well mixed and has a quasi-homogeneous density profile. However, rain falling on the surface can induce a vertical salinity gradient in the upper few meters, changing the buoyancy of the near-surface water. The initially shallow halocline formed during rain has been observed to gradually evolve into a shallow mixed layer with a lower salinity than the water below (Price, 1979; Riser et al., 2015). The strength and lifetime of such rain-induced salinity anomalies (also referred to as "freshwater lenses") depend on the vertical and horizontal mixing processes present in the near-surface layer, the air-sea heat fluxes, and the size of the rain event (Drushka et al., 2016; Katsaros \& Buettner, 1969; Soloviev \& Schlüssel, 1996; Soloviev et al., 2015). Turbulent mixing in the OSBL, caused by wind-driven shear, breaking waves, and convection, as well as ambient currents, interact with the rain-induced stratification and eventually disperse it.

Even though an estimated 78\% of the global annual precipitation occurs over the oceans (Schmitt, 1995), the response of the ocean to rain has been rarely monitored in situ. Most direct observations of rain effects in the open ocean are in tropical regions, where rainfall is frequent and intense. Rain-induced salinity anomalies here can have lateral scales of tens of kilometers (Asher et al., 2014; Soloviev \& Schlüssel, 1996; Wijesekera et al., 1999) and last for periods of a few hours (Anderson \& Riser, 2014; Brainerd \& Gregg, 1997; Reverdin et al., 2012) up to more than half a day (Walesby et al., 2015). As rainwater is typically of a different temperature than the ocean surface, it changes the local sea surface temperature and therefore the air-sea heat fluxes (Gosnell et al., 1995; Katsaros \& Buettner, 1969). Riser et al. (2015) observed two rainfall events within a dominantly evaporative region of the subtropical North Atlantic, both causing significant near-surface salinity and temperature anomalies, $\left(0.35\right.$ and $0.9 \mathrm{psu}$, and 0.3 and $0.7^{\circ} \mathrm{C}$, respectively). In the absence of rain the 
thin layer at the surface of the ocean of $O(1 \mathrm{~mm})$, known as the diffusive microlayer, has an unstable density gradient due to evaporation and net heat loss (e.g., Saunders, 1967). The smallest, nonpenetrating raindrops freshen this layer, which has a stabilizing effect and reduces air-sea exchange rates (Schlüssel et al., 1997).

While the formation and evolution of a freshwater lens both depend on the available mixing in the OSBL, its presence also modifies the near-surface turbulence (Soloviev et al., 1999). Shallow stratification isolates the water below from direct contact with the atmosphere, thereby limiting air-sea exchange to the shallow layer. Turbulence below the rain-induced stratification has been observed to rapidly decay with the onset of heavy rainfall, as the vertical flux of surface-generated turbulence is inhibited (Smyth et al., 1997). The stratification thus focuses the momentum flux from wind, waves, and rain into the shallow layer of reduced salinity. This makes the layer respond more rapidly to atmospheric forcing. Bao et al. (2003) showed an increase of surface currents of up to $0.4 \mathrm{~m} / \mathrm{s}$ in a modeled freshwater lens, an effect analogous to the surface jet formation observed within strongly stratified layers caused by diurnal warming (Brainerd \& Gregg, 1993; Callaghan et al., 2014; Sutherland et al., 2016). Such an acceleration of horizontal currents was also observed by Wijesekera et al. (1999) to occur within a large freshwater lens in the eastern tropical Pacific.

The mechanical impact of the raindrops itself is a source of turbulence in the upper centimeters of the ocean. Katsaros and Buettner (1969) observed that rainfall of larger dropsize efficiently mixes the surface, while small drops cause a larger surface salinity change. The falling raindrops "break" the surface and increase the surface stress, potentially enhancing surface renewal rates. In lab experiments artificial rain of a natural dropsize distribution has been observed to enhance turbulence in the upper $10 \mathrm{~cm}$ and increase the air-sea gas transfer velocity (Harrison et al., 2012; Turk et al., 2010; Zappa et al., 2009).

The effects of rain on the turbulent dynamics and air-water fluxes have predominantly been studied in laboratory settings. This is because in situ observations are limited due to technological challenges of measuring close to the surface, as well as the complexity of the phenomena. Rainfall events typically coincide with changes in other atmospheric forcing parameters, like reduced solar radiation and changes in wind speed (Webster et al., 1996), and the ocean's response will be the combination of all individual effects.

Although many of the physical changes to the upper ocean and air-sea exchange due to rain are known, the importance of these local changes to the coupled ocean-atmosphere system still remains uncertain. Tropical rain-induced freshwater lenses could affect the mixed layer dynamics to a similar magnitude as diurnal warming (Drushka et al., 2014). This has been shown to cause a significant error in global heat flux estimates (e.g., Clayson \& Bogdanoff, 2013). It requires a large amount of observations of individual rain events in different regions of the world's oceans to adequately characterize their variability, estimate their total impact, and appropriately parameterize rainfall effects for use in climate models.

Another reason to further quantify the magnitude and frequency of rain-induced surface anomalies is the implication for satellite remote sensing of sea surface salinity and temperature. Since the launch of the satellites Aquarius (operational from 2011 to 2015), SMOS (Soil Moisture Ocean Salinity, operational since 2010), and SMAP (Soil Moisture Active Passive, operational since 2015), the salinity of the upper few centimeters of the ocean is monitored from space using L- band radiometry (Fore et al., 2016; Lagerloef, 2012; Mecklenburg et al., 2012). A freshwater bias is often encountered in validation studies, which compare satellite-salinity to measurements from ARGO floats. This is partially explained by the fact that most ARGO floats do not measure at depths shallower than $5 \mathrm{~m}$ and therefore can miss the presence of rain-induced vertical salinity gradients (Reverdin et al., 2012). Focusing on the tropical Pacific Ocean, Boutin et al. (2013) estimated that the difference between SMOS and ARGO is linearly correlated to rain rates inferred from collocated satellite observations.

This paper describes four rain events encountered during a research campaign in the North Atlantic during which changes in the near-surface salinity, temperature, and turbulence dissipation rate were observed with the free-rising, autonomous vertical profiler ASIP (Air-Sea Interaction Profiler, see Ward et al., 2014). Although the rain events took place within a few hours of each other, the ocean response during each differed significantly. These differences in the response of the ocean surface layer are investigated through a study of the available oceanographic, atmospheric, and air-sea flux measurements. After introducing some methods used to study the rain effects on the ocean in section 2, the observational data set is presented in section 3. In section 4 the observed salinity and temperature anomalies are first discussed, followed by an investigation of how the air-sea heat and momentum fluxes changed during rain. Similarity scaling 
is used to investigate when rainfall influenced the turbulent mixing, and the changes in the turbulence dissipation rate in the upper $10 \mathrm{~m}$ are presented. A comparison is made between the observed vertical salinity anomaly $(\Delta S)$, and relationships between $\Delta S$ and rain rate derived from remote sensing efforts, an empirical model, and a prognostic model of diurnal variability in sea surface salinity. Section 5 presents a summary and discussion of the results of this study, as well as recommendations for future approaches.

\section{Background and Methods}

\subsection{Air-Sea Fluxes}

The initial formation and the evolution of a freshwater lens depend on the balance between the stabilizing buoyancy forces and the gradient dispersing turbulent mixing during and after a rainfall event. The stability of the OSBL is determined by the density profile and changes therein due to the fluxes of heat and moisture through the air-sea interface. This can be described by the surface buoyancy flux $B_{0}$, defined as

$$
B_{0}=-\frac{g}{\rho_{0}} Q_{\rho},
$$

where $g$ is the gravitational acceleration, $\rho_{0}$ a reference sea surface density, and $Q_{\rho}$ the density flux computed following Schmitt et al. (1989) and Karstensen and Lorbacher (2011):

$$
Q_{\rho}=\rho_{0}\left(\frac{-\alpha Q_{\mathrm{net}}}{\rho_{0} c_{\mathrm{pw}}}+\frac{\beta S_{0}}{\left(1-S_{0} / 1000\right)}(E-R)\right),
$$

where $Q_{\text {net }}$ is the sum of the turbulent fluxes of sensible $\left(Q_{S}\right)$ and latent $\left(Q_{L}\right)$ heat, as well as the longwave and shortwave radiative forcing $Q_{\mathrm{LW}}$ and $Q_{\mathrm{SW}}$, and is here defined positive into the ocean. The coefficients $\alpha$ and $\beta$ represent thermal expansion and haline contraction, respectively, and $c_{\mathrm{pw}}$ is the specific heat of seawater at constant pressure. $S_{0}$ is the sea surface salinity in concentration units $(\mathrm{g} / \mathrm{kg})$, and $E-R$ the net freshwater flux from evaporation and rainfall in meters per second. This formulation implies that a negative density flux (reduction of $\rho$ due to warming/freshening) corresponds to $B_{0}>0$, increasing the buoyancy of the surface mixed layer. Under the assumption that rain is at the wet-bulb temperature of the air, which is often cooler than the seawater temperature, it contributes to the sensible heat flux at the ocean surface. For use in a bulk-flux algorithm this additional heat flux term $Q_{\mathrm{Sr}}$ is defined as (Fairall et al., 1996)

$$
Q_{\mathrm{Sr}}=\rho_{r} c_{\mathrm{pw}} R \alpha_{w}\left(\Delta T+\frac{\Delta q L_{e}}{c_{\mathrm{pa}}}\right),
$$

where $\rho_{r}$ is the density of rainwater falling at rate $R, c_{\mathrm{pw}}$ and $c_{\mathrm{pa}}$ are the specific heat of water and air, respectively, $\Delta T$ and $\Delta q$ are the sea-air temperature and specific humidity differences, respectively, $L_{e}$ is the latent heat of evaporation, and $\alpha_{w}$ is the Clausius-Clapeyron wet-bulb factor (Gosnell et al., 1995).

Precipitation often occurs together with changes in the wind conditions. The characteristics of the atmospheric front in which rain clouds develop determine whether surface wind speed increases or decreases during a rain event (Webster et al., 1996). Variability in the wind-driven momentum flux into the ocean, $\tau_{w}$, has a direct effect on the available energy for vertical mixing and waves. Rain carried by the wind will have acquired both vertical and horizontal momentum when hitting the surface, producing an additional momentum flux. The horizontal momentum of the falling raindrops in windy conditions can be represented with the surface stress $\tau_{r}$, linearly related to the rain rate and the $10-\mathrm{m}$ wind speed $U_{10}$ (Caldwell \& Elliott, 1971):

$$
\tau_{r}=0.85 U_{10} \rho_{r} R
$$

Raindrops that break through the surface create splashes, jets, bubbles, and small waves, increasing the turbulent mixing directly below the surface (Liu et al., 2017; Schlüssel et al., 1997; Tsimplis, 1992). This can be described with a kinetic energy flux $\left(E_{k}\right)$, computed as a function of the terminal velocity of raindrops and the dropsize distribution, for which often the rain rate-dependent Marshall-Palmer distribution (Marshall $\&$ Palmer, 1948) is used. The exact solution for $E_{k}$ (Schlüssel et al., 1997; Soloviev \& Lukas, 2014) can be approximated with a power law fit (Bellenger et al., 2017):

$$
E_{k}(R)=m R^{n} .
$$

For a range of $R=0: 80 \mathrm{~mm} / \mathrm{h}, m=0.4 \times 10^{-3}$ and $n=1.3$. On dimensional grounds the kinetic energy flux can be translated into a surface stress as well (Schlüssel et al., 1997):

$$
\tau_{k}=\rho_{w}^{1 / 3} E_{k}^{2 / 3} .
$$




\subsection{Models of Rain-Induced Salinity Anomalies}

The vertical salinity gradient, and the subfootprint scale variability of freshwater lenses cause biases in the validation of remote sensing measurements with in situ observations (Boutin et al., 2014; Drucker \& Riser, 2014). Linear relationships between rain rate and the vertical salinity anomaly $\Delta S$ have been inferred from several validation studies of the SMOS and Aquarius satellites:

$$
\Delta S=c R,
$$

where the rain freshening constant $c$ has been found to range from 0.07 to 0.36 (Boutin, 2016). These validation studies concern tropical and subtropical ocean regions only, where rain rates can be high and salinity is an important factor in controlling the upper ocean stratification. The wide range of $c$ implies that there is a large variability in conditions that is not explained by the simple relationship in equation (7) and suggests that $\Delta S$ is not only a function of $R$.

The representation of the upper ocean salinity response to rain by the General Ocean Turbulence Model (GOTM; www.gotm.net; Burchard et al., 1999; Umlauf \& Burchard, 2005) has been investigated by Drushka et al. (2016). GOTM is a one-dimensional model, which solves the vertical transport equations of momentum and scalar tracers. Drushka et al. (2016) used this model with a $k-\epsilon$ second-moment turbulence closure scheme. A 100-m vertical domain, with resolution increasing from $1.5 \mathrm{~m}$ to $<5 \mathrm{~cm}$ near the surface, was initialized based on observed $T$ and $S$ profiles and forced at the surface with meteorological parameters at a 10-s time step. Comparison to several observational data sets has shown that this setup of GOTM is able to accurately describe the evolution of the salinity, temperature, and dissipation rate profiles in the upper ocean under rainfall. Sensitivity tests resulted in an empirical relation for the rain-induced salinity anomaly as a function of both rain rate and wind speed:

$$
\Delta S_{\max }=a R_{\max } \bar{U}^{-b} .
$$

where $\Delta S_{\max }$ is the maximum salinity difference between a reference depth and the surface following a rain event, $R_{\max }$ is the peak rain rate, and $\bar{U}$ the mean wind speed during the event. Forcing the model with a range of constant $\bar{U}$ and 1-hr Gaussian pulses of rain with peak value $R_{\max }$ has resulted in the empirical coefficients $a=0.11 \pm 0.03$ and $b=1.1 \pm 0.03$.

A prognostic model designed to include diurnal warming of the sea surface temperature in numerical weather prediction and climate models was presented by Zeng et al. (2005). This model has recently been adapted by Bellenger et al. (2017) to also represent rainfall effects on temperature and salinity of the sea surface diffusive microlayer and the near-surface layer. From an input of surface heat and freshwater fluxes, wind stress, and bulk-seawater $S$ and $T$, the scheme computes the integral of the one-dimensional vertical salinity and heat budgets in the upper $3 \mathrm{~m}$. This results in the differences $\Delta S$ and $\Delta T$ between the subskin level and the bottom of a freshwater lens, assuming an exponential profile with wind-speed-dependent curvature. The vertical mixing over the layer is parameterized with a turbulent diffusion coefficient as in Large et al. (1994), which uses a stability function based on similarity scaling. The interfacial values $S_{\text {skin }}$ and $T_{\text {skin }}$ are determined assuming that the vertical gradient of $S$ and $T$ over the microlayer is a linear function of the net freshwater flux and heat flux over this layer, respectively, as in Saunders (1967). The depth of the microlayer is inversely related to the total friction velocity, which is computed from the sum of $\tau_{w}, \tau_{r}$ and $\tau_{k}$.

\section{Data}

Measurements were collected during an oceanographic campaign aboard the R/V Knorr in the early summer of 2011 in the North Atlantic. The ship went from Woods Hole MA toward the south of Greenland (Figure 1). The main goal of this campaign was to acquire an observational data set of surface ocean properties and air-sea fluxes during phytoplankton blooms through a combination of meteorological, wave, and whitecap measurements, as well as direct measurements of temperature, salinity, and turbulence in the near-surface layer of the ocean (see also Bell et al., 2013, 2017; Esters et al., 2017; Scanlon \& Ward, 2016; Scanlon et al., 2016; Sutherland et al., 2013).

\subsection{Microstructure Measurements}

Microstructure profiles of the upper $60 \mathrm{~m}$ of the water column were obtained with the ASIP. This autonomous vertical profiler measures microstructure temperature $(T)$ and conductivity $(C)$ with two 


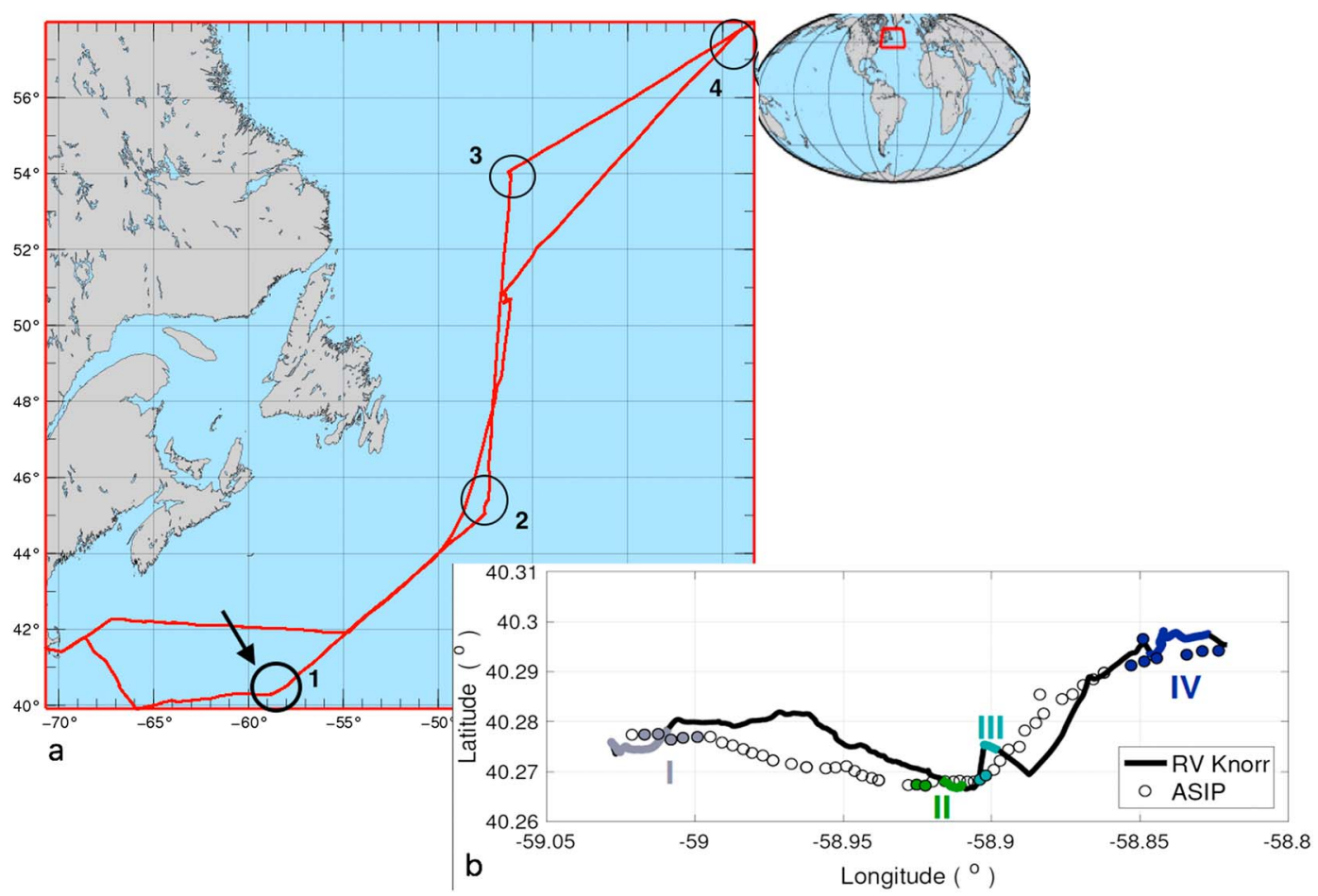

Figure 1. (a) Map of the ship track of the Knorr-11 cruise, with circles indicating the approximate locations of Air-Sea Interaction Profiler (ASIP) deployments. Observations from deployment 1 are used in this paper. (b) The exact location of the ASIP profiles, with colors indicating the sections of both the ASIP and the ship track corresponding to the rainy periods.

FP07-thermistors and an SBE-7 microstructure conductivity sensor, respectively. These microstructure sensors require in situ calibration, for which a slow-response $C / T$ sensor (Neil Brown Ocean Sensors Inc.) with long-term stability is mounted on the side of the ASIP. The accuracy of the NBOSI $C / T$ sensor is $0.001 \mathrm{~S} / \mathrm{m}$ and $0.005^{\circ} \mathrm{C}$ (http://www.neilbrownoceansensors.com/CT).

The microstructure sensors are mounted on the upward facing side of the profiler, and the surface level can be determined with an accuracy of $\sim 1 \mathrm{~cm}$ thanks to the fast response of the conductivity probe (see also Ward et al., 2014). Salinity $S$ is derived using $1 \mathrm{~cm}$ vertically bin averaged profiles of microstructure $C$ and $T$.

Two SPM-38 velocity shear probes provide profiles of orthogonal components of the vertical shear of the horizontal turbulent velocity. To convert the time derivative of the velocity fluctuations to a spatial derivative Taylor's frozen field theorem is used. This is possible when assuming that the shear probes travel through the water at a constant velocity. The ASIP's rise velocity was $0.6 \pm 0.04 \mathrm{~m} / \mathrm{s}$. Assuming that the turbulence is isotropic, the turbulent dissipation rate $\epsilon$ is then conventionally computed from the integral of the shear $\operatorname{spectra} \psi_{z}$ :

$$
\epsilon=\frac{15}{2} \int \psi_{z}(k) \mathrm{d} k
$$

where $k$ is the wave number. Mean shear spectra are computed for 90 -cm long, half-overlapping sections of a vertical profile, resulting in an $\epsilon$ value every $45 \mathrm{~cm}$. To include variance beyond the resolved part of the shear spectra, a Nasmyth universal spectrum is fitted to the inertial subrange of the measured spectrum (Lueck, 2016; Macoun \& Lueck, 2004; Oakey, 1982).

In open-ocean conditions the ASIP is assumed to be a semi-Lagrangian instrument; the profiler will be moving along with a specific water mass and thus is expected to capture its response to changes in the surface forcing. In this study measurements obtained during the first deployment of the ASIP during the Knorr-11 campaign are used. A total of 58 profiles were obtained between 26 June 18:30 hr and 27 June 12:15 hr (local mean time), at the approximate location indicated by “1" in Figure $1 \mathrm{a}\left(\sim 40.27^{\circ} \mathrm{N}, 58.9^{\circ} \mathrm{W}\right)$. 
Table 1

Characteristics of the Four Observed Rain Events: Peak Rain Rate $R_{\text {max }}$, Cumulative Rain $R_{\text {tot }}$, Duration $t_{\text {rain }}$, Mean and Maximum 10- $m$ Wind Speed $U_{10}$ During the Rain Event

\begin{tabular}{lccccccc}
\hline$\#$ & $R_{\max }(\mathrm{mm} / \mathrm{h})$ & $R_{\text {tot }}(\mathrm{mm})$ & $t_{\text {rain }}(\min )$ & $\overline{U_{10}}(\mathrm{~m} / \mathrm{s})$ & $U_{10 \max }(\mathrm{m} / \mathrm{s})$ & $\Delta S_{\max }(\mathrm{psu})$ & $\Delta T_{\max }\left({ }^{\circ} \mathrm{C}\right)$ \\
\hline I & 20 & 4.4 & 96 & 7.1 & 10.2 & -0.07 & -0.01 \\
II & 15 & 2.6 & 45 & 9 & 10.7 & -0.02 & -0.04 \\
III & 72 & 14.6 & 45 & 7.8 & 9.6 & -0.15 & +0.03 \\
IV & 45 & 18.4 & 135 & 6 & 8.6 & -0.57 & -0.07 \\
\hline
\end{tabular}

Note. Observed maximum vertical salinity and temperature anomaly $\Delta S_{\max }, \Delta T_{\max }$ between the shallowest ASIP measurement and a depth of $5 \mathrm{~m}$. ASIP $=$ Air-Sea Interaction Profiler.

\subsection{Meteorology and Air-Sea Fluxes}

An eddy covariance system was installed on the bow mast of the research vessel, consisting of two CSat3 sonic anemometers and a 3-D inertial motion unit, to correct the wind measurements for ship motion (Landwehr et al., 2015; Miller et al., 2009). The setup resulted in direct estimates of momentum, heat, and gas fluxes (Bell et al., 2013, 2017). Meteorological observations were made with a Vaisala WXT520 weather system, which was also mounted on the bow mast. Rain intensity was recorded over 10-s intervals. The meteorological observations further consisted of wind speed, wind direction, downwelling shortwave and longwave radiation, air temperature, barometric pressure, and relative humidity. These data were used to compute heat and momentum fluxes using the COARE 3.0 bulk flux algorithm (Fairall et al., 1996, 2003). The algorithm was run for an input time series at 2-min resolution, to ensure that the rain rates and the rapid variability in other parameters associated with the passing of a rain event was retained. Instead of bulk-temperature and salinity from the ship intake, a time series from the interpolated record of the average $T$ and $S$ in the top $5 \mathrm{~cm}$ observed with the ASIP was used. This was done to improve the flux computations (avoiding the need for a warm layer correction). A significant warm bias of the ship's thermosalinograph record due to heating of intake water also meant that the ASIP $T / S$ record was deemed more reliable for the flux computations.

As can be seen in Figure $1 \mathrm{~b}$ the vessel remained in the vicinity of the profiler for the duration of the ASIP deployment, the average distance between the ASIP and the ship is $900 \mathrm{~m}$ and never more than 1,500 $\mathrm{m}$. Therefore, the atmospheric conditions of the profiler's location are expected to be well represented by the meteorological measurements from the ship. Rain of various intensity occurred during the measurement period. Four rain events are identified, each of an intensity larger than $10 \mathrm{~mm} / \mathrm{hr}$ and a duration long enough for a minimum of two ASIP profiles to take place. Characteristics of the rain events are listed in Table 1 . The highest difference in $S$ and $T$ between the subsurface $(1 \mathrm{~cm})$ and a depth of $5 \mathrm{~m}$ is also listed, which will be used in the comparison to the predicted values following equations (8) and (7) (section 4.4).

\subsection{Wave Observations}

One-dimensional spectra of surface gravity waves, from which the significant wave height $H_{\text {sig }}$ and the wave spectral energy can be derived, were measured using an ultrasonic altimeter in combination with a motion correction device. These were mounted at the end of a steel pole, pointing down from a hole on the bow of the research vessel (see Christensen et al., 2013 for a detailed description). The waves measured were limited to the frequency band $f=0.05-0.4 \mathrm{~Hz}$; the high-frequency tail of the wave spectrum, to which the rain is thought to have a dampening effect (Cavaleri et al., 2015; Peirson et al., 2013; Tsimplis \& Thorpe, 1989), was not within the resolution of the sensor.

\section{Results}

4.1. Salinity, Temperature, and Density Anomalies

To illustrate the magnitude and shape of the near-surface anomalies caused by each rain event, the profiles of $S, T$, and the potential density $\sigma$, reduced by their value at $8 \mathrm{~m}$ below the surface, are presented in Figure 2 . This reference depth of $8 \mathrm{~m}$ was chosen after visual inspection of the ASIP profiles, because it was the deepest level above which the surface water was well mixed before any of the four rain events. For each event the profile corresponding to the maximum salinity anomaly between the surface and a depth of $5 \mathrm{~m}\left(\Delta S_{\max }\right)$, as well as three or four other profiles are plotted. The strongest reduction in surface salinity took place during 


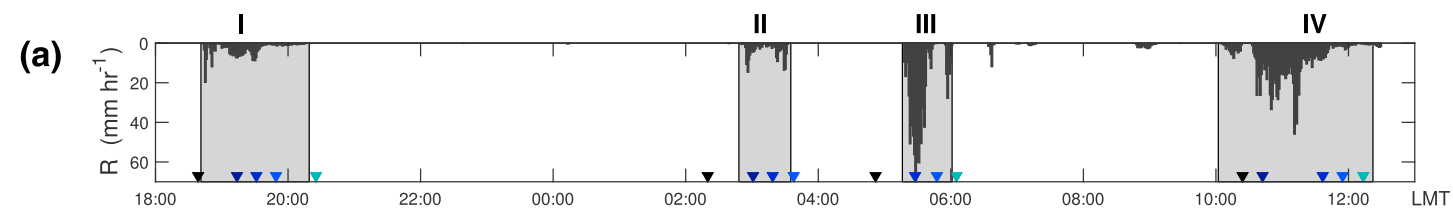

(b)
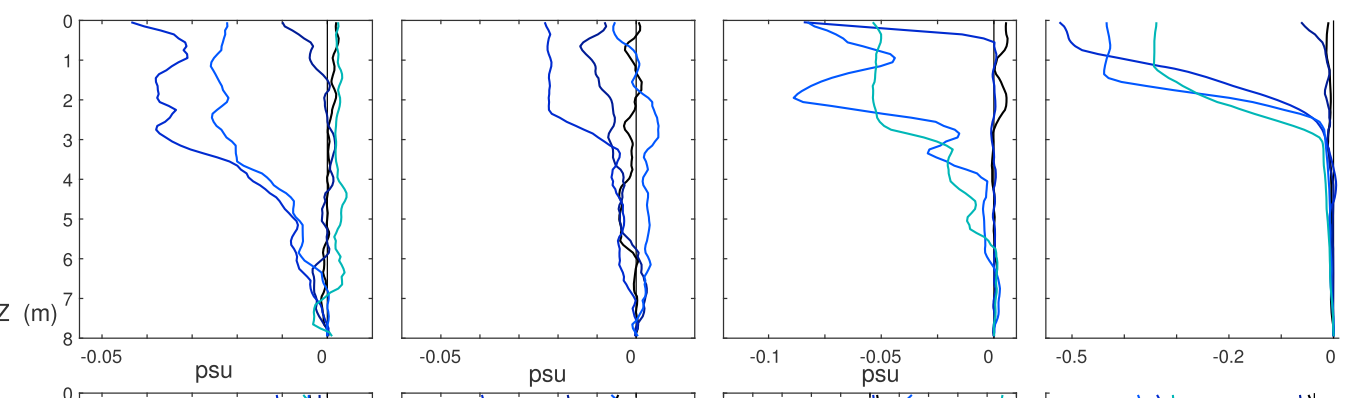

(c)
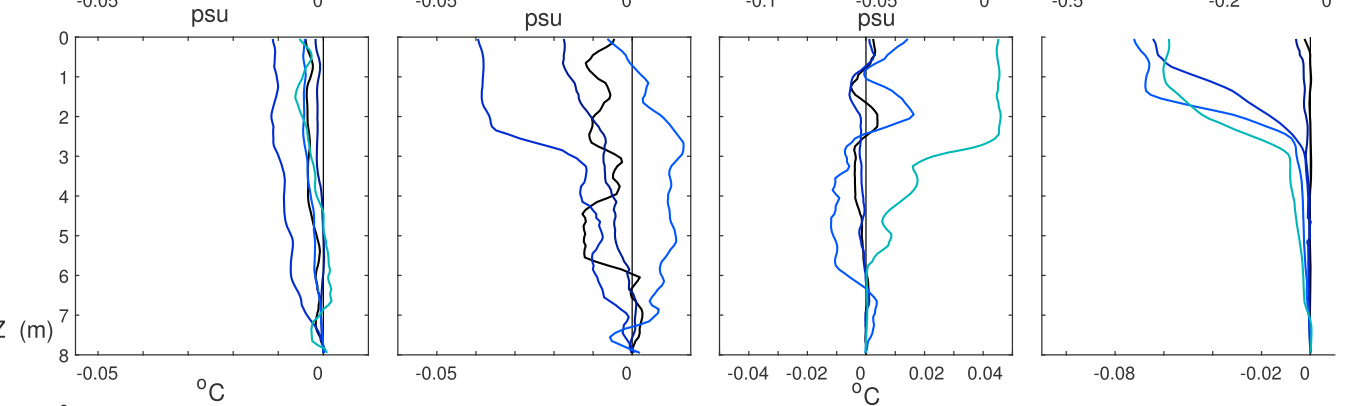

(d)
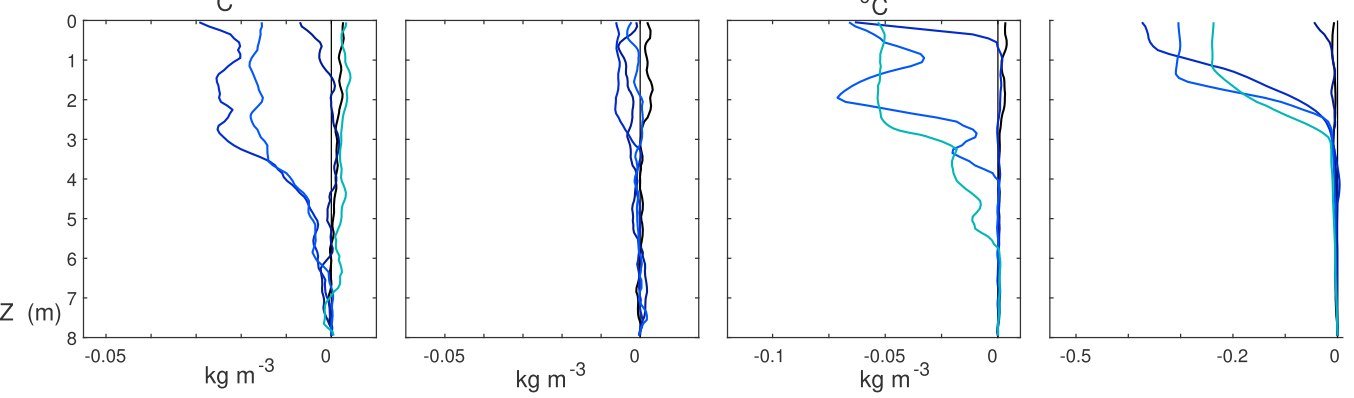

Figure 2. (a) Time series of rain rate $R$. (b-d) Near-surface profiles of, respectively, salinity $(S)$, temperature $(T)$, and potential density $(\sigma)$ reduced by their value at $8 \mathrm{~m}$, at several times during each of the four rain events. The colored triangles in panel (a) indicate the times of the corresponding profile in panels (b)-(d) for each rain event.

rain event IV, with $\Delta S_{\max }=-0.57 \mathrm{psu}$. This rain event, containing the largest volume of freshwater $\left(R_{\mathrm{tot}}\right.$ in Table 1), also caused cooling of the ocean surface of $-0.07^{\circ} \mathrm{C}$. A higher-peak rain rate $R_{\max }$ was recorded during rain event III, but the associated salinity anomaly was only $-0.15 \mathrm{psu}$, and a slight temperature increase was measured over the upper $8 \mathrm{~m}$. Rain events I and II were both smaller in terms of peak rain rate and total rain volume; these resulted in only small vertical salinity anomalies of -0.07 and $-0.02 \mathrm{psu}$ and temperature anomalies of -0.01 and $-0.04^{\circ} \mathrm{C}$, respectively.

The timing of the steepest salinity gradient with respect to the onset of the rain varied between the rain events, from $0.5 \mathrm{hr}$ in rain event III up to $1.5 \mathrm{hr}$ in rain event IV. During each of the rain events the freshwater was gradually mixed down and formed a shallow rain-induced mixed layer as described in Price (1979). The rain-induced freshening contributed most to the change in near surface density; the absolute ratio of density anomalies caused by salinity $\left(\Delta \rho_{S}=\rho_{0} \beta \Delta S_{\max }\right)$ and temperature $\left(\Delta \rho_{T}=-\rho_{0} \alpha \Delta T_{\max }\right)$ was 13.1, 1.6, 12.4, and 21.0 for the four rain events. This is also illustrated by the similarity in the shape and magnitude of the $\Delta \sigma_{0-8 m}$ and $\Delta S_{0-8 m}$ profiles in Figure 2, for all rain events except rain event II; in the latter the temperature anomaly is of a magnitude that compensates the freshening.

In Figure 3 the $T-S$ relationships during each of the rain events is evaluated for the upper $25 \mathrm{~m}$, before, during, and a short time after the actual rainfall. The profiles show a temperature maximum corresponding to a warmer, saltier layer between 15 and $25 \mathrm{~m}$. Above this lies the well-mixed surface layer in which the $T$-S 

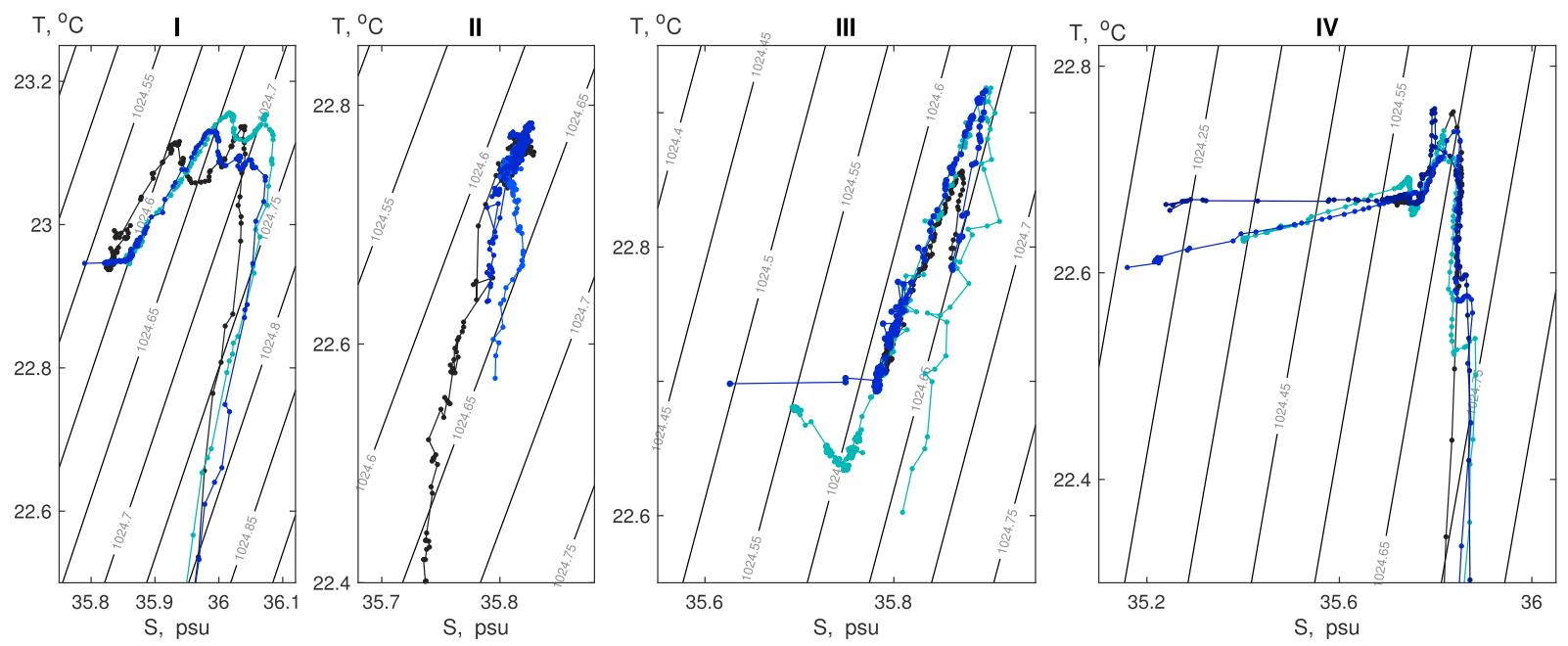

Figure 3. $T$-S curves of the upper $25 \mathrm{~m}$, during the rain events I, II, III and IV. Colors in each panel correspond to those of the profiles in Figure 2. The $T$-S relationship is evaluated at each 20 -cm interval. Due to the overall cooling of the near-surface layer the temperature scale on the vertical axis in the panel of rain event I differs from the other three.

relation is aligned to the $1,024.6-\mathrm{kg} / \mathrm{m}^{3}$ isopycnal. The $T$-S curves strongly deviated from this isopycnal in at least one profile taken during rain events I, III, and IV, instead lying along a nearly horizontal line in the direction of zero salinity. Such a $T$-S relation near the surface was hypothesized by Wijesekera et al. (1999), and clearly shows the dilution by the rainwater. The observed warming of the near-surface water during rain event III is also clearly visible in Figure 3 . This is remarkable because it is generally expected that rain, falling from high altitude, forms a source of cool water to the ocean.

\subsection{Meteorology and Air-Sea Fluxes}

Time series of the meteorological forcing and air-sea fluxes during the ASIP deployment are shown in Figure 4 . The wind, from a south to southwesterly direction, varied in strength over this period with a range of 3 to $10 \mathrm{~m} / \mathrm{s}$ (Figure $4 \mathrm{a}$ ). Moderate winds during rain event I were followed by a 30-min wind speed peak toward the tail of this event, whereas wind speed peaks occurred at the same time as rain rate peaks during events II and III. Rain event IV coincided with a significant reduction in wind speed, but wind speeds increased again toward the end of the rain event.

The significant wave height $H_{\text {sig }}$ was low to moderate (Figure 4b), between 1.6 and $2.2 \mathrm{~m}$, with the highest value recorded at the time of rain event II. In Figure $4 \mathrm{c}$ it can be seen that the air temperature $T_{\text {air }}$ varied within a $3{ }^{\circ} \mathrm{C}$ range during the observational period, in association with the rain events. This resulted in the sea-air temperature difference $\Delta T_{\text {sea-air }}$ to reverse sign several times.

The occurrence of rain and associated changes in other meteorological variables modulated the air-sea heat fluxes. Figure $4 \mathrm{~d}$ shows the time series of the outgoing latent heat flux $\left(Q_{\mathrm{L}}\right)$, sensible heat flux $\left(Q_{\mathrm{S}}\right)$, and longwave radiative flux $\left(Q_{\mathrm{LW}}\right)$ computed with COARE 3.0 (each flux component here is defined positive from sea to air). The variability of $\Delta T_{\text {sea-air }}$ caused the change of sign of $Q_{\mathrm{S}}$, which was the smallest heat flux component. The computed rain sensible heat flux $Q_{\mathrm{Sr}}$ following equation (3) formed a significant component to the heat balance during rain events III and IV. Changes in the wind speed were the main cause of the strongly varying latent heat flux during and shortly after the rain events. During clear sky conditions $Q_{\mathrm{LW}}$ is generally highest, and it is observed in Figure $4 \mathrm{~d}$ to have reduced to zero or negative values during the rain events. The net sea-to-air heat flux $Q_{\text {out }}$ increased significantly during three of the four rain events. However, the dominant component responsible for this increase was not the same for each event: The two largest peaks in $Q_{\text {out }}$, which occurred during rain events II and IV, were driven by an increase in $Q_{\mathrm{L}}$ and $Q_{\mathrm{Sr}}$, respectively. An increase in the latent heat flux is also observed after rain event I. Rain event III contains both processes, a small peak caused by $Q_{\mathrm{Sr}}$ during rainfall and an increase in $Q_{\mathrm{L}}$ directly afterward.

From the time series of the downward solar radiation $Q_{\mathrm{SW}}$ (Figure 4e) it can be inferred that the first two rain events took place during the night, event III shortly after sunrise, and event IV occurred during daytime conditions. There was a strong reduction in $Q_{\mathrm{Sw}}$ during both events. The net heat fluxes and freshwater 

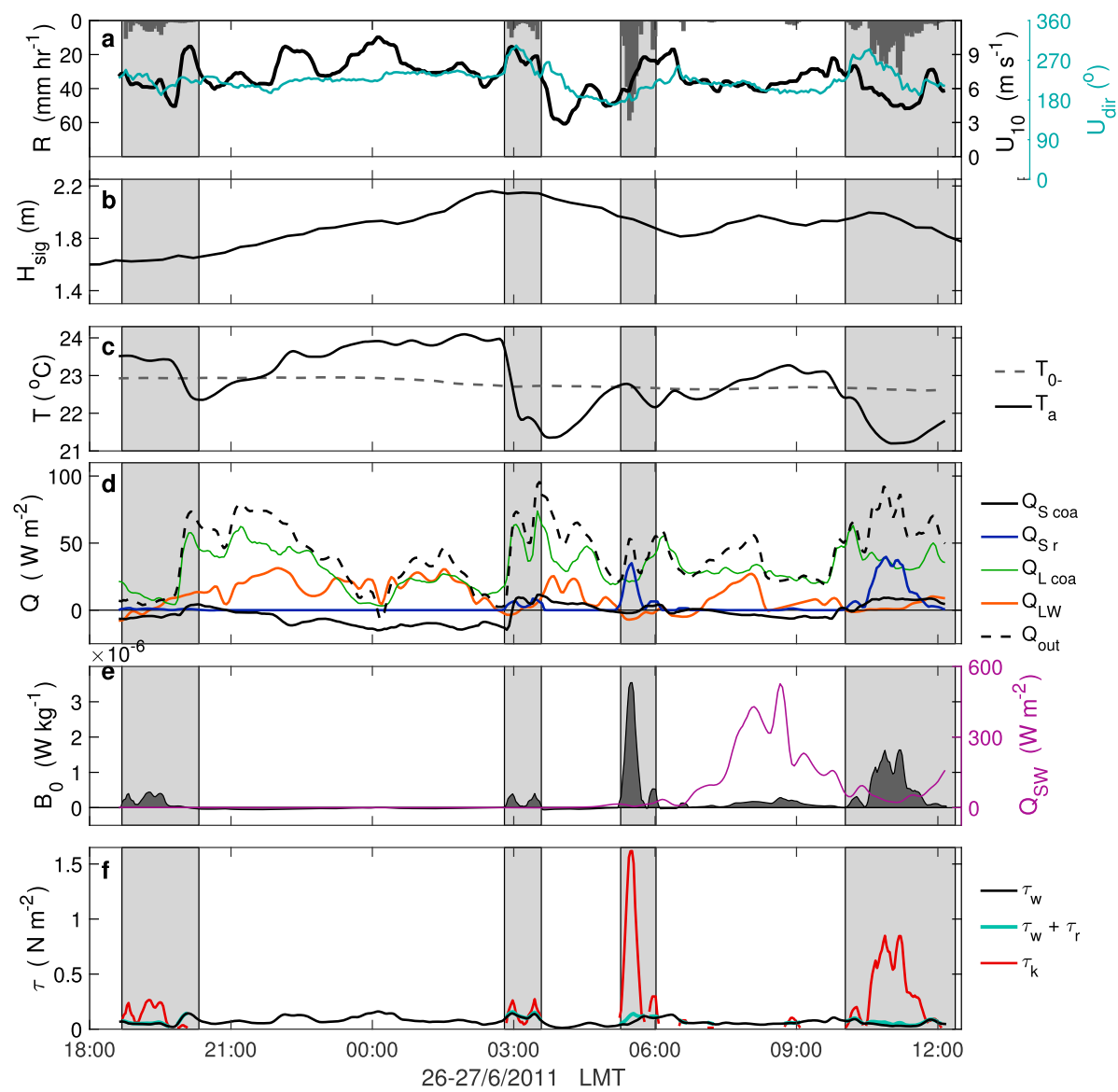

Figure 4. Time series of meteorological observations and computed air-sea fluxes during the deployment of the ASIP: (a) rain rate $R$ (left axis), 10-m wind speed $U_{10}$, and its direction $U_{\text {dir }}$. (b) Significant wave height $H_{\text {sig. }}$. (c) Interpolated subskin sea surface temperature $T_{0-}$ (mean over upper $1 \mathrm{~cm}$ of ASIP profiles) and air temperature $T_{a}$. (d) Air-sea sensible heat flux $Q_{S}$, latent heat flux $Q_{L}$, and net longwave radiation $Q_{\mathrm{LW}}$ computed using the COARE 3.0 algorithm. Also shown are the rain-induced heat flux following equation (3) $Q_{\mathrm{Sr}}$, and the sum of the outgoing heat fluxes $Q_{\text {out }}$. (e) Surface buoyancy flux $B_{0}$ (shaded area, defined positive into the ocean) and downward shortwave radiation $Q_{\mathrm{Sw}}$. (f) Surface stress due to the horizontal momentum of the wind $\left(\tau_{w}\right)$, wind plus rain $\left(\tau_{w}+\tau_{r}\right)$, and due to the kinetic energy of the raindrops $\left(\tau_{k}\right)$. Gray shading in each panel indicates the rainfall periods. ASIP $=$ Air-Sea Interaction Profiler.

fluxes lead to the computation of $B_{0}$ from equation (1), the time series of which is shown in Figure 4e. Under nonrain conditions, the buoyancy of the surface water was controlled by the diurnal cycle of the heat flux; during rain the haline component in $B_{0}$ was dominant, positively enhancing the total buoyancy input by an order of magnitude.

The surface momentum flux represented by the wind stress $\tau_{w}$, the rain-induced surface stress $\tau_{r}$, and the kinetic energy of falling raindrops $\tau_{k}$, as defined in equations 4 and (6), are computed for the period of the ASIP deployment and are shown in Figure $4 \mathrm{f}$. The sum of $\tau_{r}+\tau_{w}$ is shown to have increased the momentum flux by a factor 1.1-2.5 during the observed rainfall events. The associated velocity scales $u_{*_{w}}$ and $u_{*_{r}}$ are thought to influence the total rain-induced mixed layer (Bellenger et al., 2017) and the evolution of the freshwater lens. The conceptual surface roughness due to the kinetic energy of surface penetrating raindrops corresponds to a stress an order of magnitude larger than $\tau_{w}$. Rain-induced velocity fluctuations can contribute to mixing the water in the upper $10 \mathrm{~cm}$. However, it has been shown that the majority of $E_{k}$ dissipates within the upper centimeter below the surface (Harrison \& Veron, 2017).

\subsection{Turbulence During Rain}

Under the assumption of a steady state and isotropic turbulence, $\epsilon$ is equal to the production of turbulence from buoyancy and shear forces (Osborn \& Cox, 1972). Profiles of $\epsilon$ in Figure 5b are used to observe the evolution of upper ocean turbulence during the study period, which was highly intermittent in the upper $10 \mathrm{~m}$ 

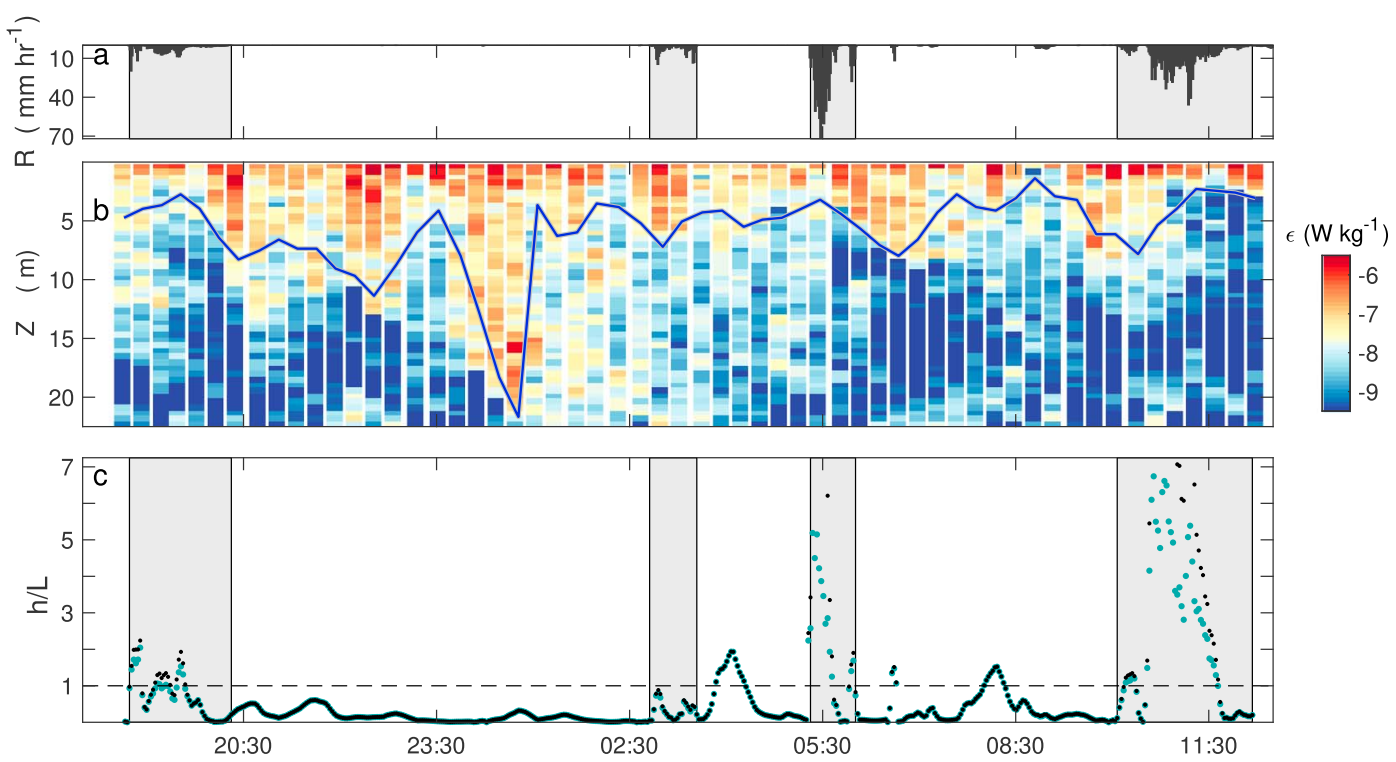

Figure 5. (a) Time series of rain rate. (b) The 58 profiles of turbulence kinetic energy dissipation rate $\epsilon$ measured with the Air-Sea Interaction Profiler. The blue line shows the mixing layer depth, XLD, determined with a threshold criterion of $1 \times 10^{-8} \mathrm{~W} / \mathrm{kg}$. (c) The ratio of the XLD and the Monin-Obukhov length $L_{\mathrm{MO}},\left|h / L_{\mathrm{MO}}\right|$ with $h=X L D$, in which $L_{\mathrm{MO}}$ is computed with either $\tau_{w}$ (black dots) or $\tau_{w}+\tau_{r}$ (blue-green dots).

especially; several periods of enhanced turbulence in the near-surface layer occurred. The depth of active turbulent mixing, also known as the mixing layer depth (XLD), can be determined from the $\epsilon$ profiles by finding the depth below the surface in each profile where $\epsilon$ reduces to a background value (Sutherland et al., 2014). For this observational period $\epsilon=1 \times 10^{-8} \mathrm{~m}^{2} / \mathrm{s}^{3}$ best represented the threshold value below which turbulence reduces to the background state. A major deepening of the XLD is observed around 00:00 hr, which is thought to be related to the passing of a front. At other times the enhanced turbulence coincided with peaks in the wind speed. It is therefore hypothesized that the near-surface turbulence was mainly driven by wind-induced shear and wave effects. During nighttime, convectively driven turbulence will likely have played an important role too, due to a net buoyancy flux out of the ocean. The XLD is observed to have shoaled during the first half of rain events I, III, and IV, possibly as a result of the dampening of Turbulent Kinetic Energy (TKE) by the enhanced positive surface buoyancy flux during rain.

Using similarity scaling, a depth below the surface where the buoyancy and momentum fluxes are equally effective at controlling turbulence is defined as (Large et al., 1994; Lombardo \& Gregg, 1989; Monin \& Obukhov, 1954)

$$
L_{\mathrm{MO}}=\frac{u_{*}^{3}}{\kappa B_{0}},
$$

the Monin-Obukhov length, where $\kappa$ is the Von Karman constant $\sim 0.4$, and $u_{*}$ is the waterside friction velocity, equal to $\sqrt{\tau / \rho_{w}}$. The ratio $h / L_{\mathrm{MO}}$ can be used to verify whether the turbulent mixing over the layer $h$ is dominantly wind or convectively driven (Weller et al., 2002). Figure $5 \mathrm{c}$ illustrates the absolute value of this ratio, where $L_{\mathrm{MO}}$ is computed using either $\tau_{w}$ or the sum of $\tau_{w}$ and $\tau_{r}$, and $h=X L D$ is used. The ratio $\left|h / L_{\mathrm{MO}}\right|<1$ during nighttime and minimum values coincide with periods of mixing layer deepening, which indicates that the turbulence near the surface is dominantly wind driven. Only for a short period after rain event II nighttime convection is dominant, following a reduction in $\tau_{w}$ (see Figure $4 \mathrm{f}$ ). Once $B_{0}$ changed sign in the morning $\left|h / L_{\mathrm{MO}}\right|>1$, and the same happened during rain events I, III, and IV. At these times the turbulence over the mixing layer depth was temporarily suppressed by the stabilizing buoyancy flux. Using $u_{*}=\sqrt{\left(\tau_{w}+\tau_{r}\right) / \rho}$ in (10) increased $L_{\mathrm{MO}}$ by a factor $1.2-4$, and consequently reduced $\left|h / L_{\mathrm{MO}}\right|$ during the rain events.

The presence of a shallow stratified layer can dampen turbulent mixing and inhibit downward transport of turbulence in the upper ocean (Smyth et al., 1997). A second possible consequence of the stratification is that the surface momentum flux from the wind and waves will be focused into a shallow layer. To further 


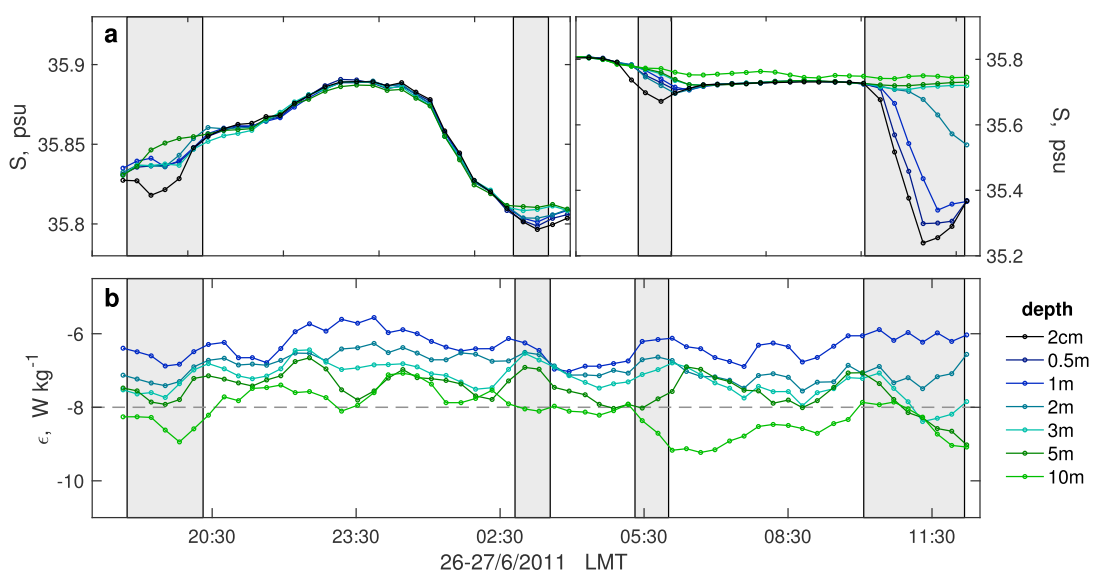

Figure 6. (a) Salinity $S$ at selected depths below the surface. (b) Turbulence kinetic energy dissipation rate $\epsilon$ at approximately the same depths as in panel (a). The limits of the $y$ axis in panel (a) are reduced in the first half of the time series to improve the resolution for the small salinity anomalies. Dashed line in panel (c) is the threshold level used to define the mixing layer depth. Gray shading in each plot indicates the periods of the four rain events.

illustrate the evolution of $\epsilon$ and $S$ during rainfall, both time series are shown for different levels in the upper $10 \mathrm{~m}$ in Figure 6. Focusing on the fresh water lens formation during rain event IV, it is observed that an initial increase in $\epsilon$ before and at the start of the rain was followed by a decrease of $\epsilon$ below the upper meter. The reduction in $\epsilon$ in the upper $3 \mathrm{~m}$ coincided with the first half of the rain event, until the peak rain rate and the associated maximum in $B_{0}$ (see Figure 4e), during which $\left|h / L_{\mathrm{MO}}\right|>1$; this further illustrates that the turbulence near the surface was suppressed by the rain induced stratification. As soon as $0<\left|h / L_{\mathrm{MO}}\right|<1$ the momentum of the wind was large enough to break down some of the stratification. At the end of the time series the upper meter is well mixed and a salinity gradient remains between 1 and $3 \mathrm{~m}$. Below this level the turbulence continues to decrease until the end of the observational period. At 5 and $10 \mathrm{~m} \epsilon$ is reduced by approximately 2 orders of magnitude compared to the pre-rain level, while the shallow surface layer responds to wind forcing.

The observed salinity anomaly caused by rain event III is smaller at all depths, causing a weak stratification to form between 2 and $10 \mathrm{~m}$. Nevertheless, a small reduction in $\epsilon$ was observed at $10 \mathrm{~m}$. Turbulence increased at all depths above this level, in response to the increased wind forcing. Although $\left|h / L_{\mathrm{MO}}\right|$ indicates that buoyancy controls the turbulence during the first half of rain event III, this is not reflected in a reduction of $\epsilon$ in the fresh layer.

The rain-induced freshening by rain events I and II was even smaller and had therefore no measurable effect on the turbulent mixing of the near-surface layer; the evolution of $\epsilon$ was similar at all depth levels, driven by changes in wind speed only.

\subsection{Model Validation}

\subsubsection{Numerical Models}

The salinity anomalies observed during the four rain events are compared to those predicted by the empirical model in Drushka et al. (2016). For each rain event the measured peak rain rate $R_{\max }$ and mean wind speed $\bar{U}$ over the duration of the event are used to compute $\Delta S_{\max }$ with the parameterization in equation (8).

Figure 7 compares the outcome of the parameterization to the observed $\Delta S_{\max }$ over the top $5 \mathrm{~m}$ (circles). The computed $\Delta S_{\max }$ overestimates the observed $\Delta S_{\max }$ for all rain events. Especially for event III the parameterization predicts a much stronger salinity anomaly $(+0.6 \mathrm{psu})$ than was observed.

The strength of vertical mixing at the mean wind speed observed during this event is underestimated by the empirical model. Several reasons can be given for this result, illustrating that the empirical model is an oversimplification of reality. The relation in (8) was determined from sensitivity tests of $\Delta S_{\max }$ versus $R_{\max }$ and $\bar{U}$. However, wind speed is seldom constant during a rain event-the meteorological time series presented here (Figure 4), show that event II and III were typical of squalls (Smyth et al., 1997), as the rain coincided with wind gusts. Figure 7 therefore also shows $\Delta S_{\max }$ when instead of $\bar{U}$ as an upper bound to the wind forcing $U_{\max }$ is used in (8). This reduces the bias in $\Delta S_{\max }$, especially for rain event IV. 


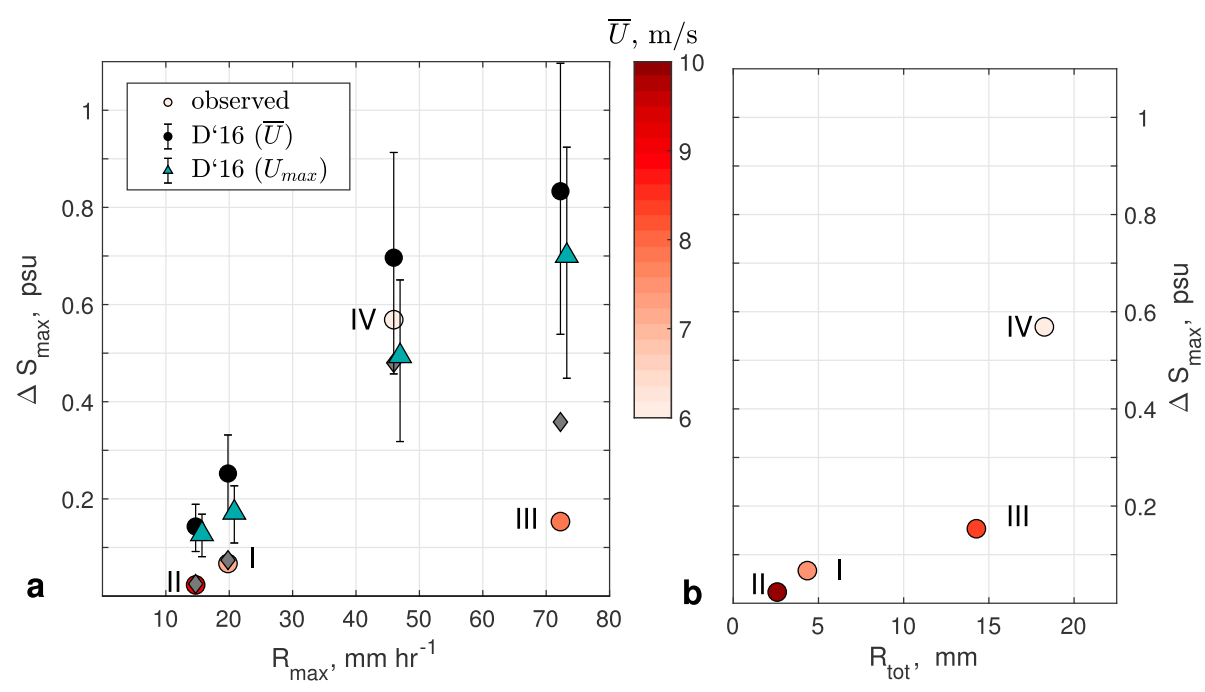

Figure 7. (a) Maximum vertical salinity difference $\Delta S_{\max }$ versus peak rain rate $R_{\max }$ for each rain event, computed between 5 and $2 \mathrm{~cm}$ of Air-Sea Interaction Profiler profiles (circles), as well as resulting from the prognostic model in Bellenger et al. (2017) (B'17, diamonds). Color coding of observations represents mean wind speed $\bar{U}$. Black circles and green triangles and their error bars are the predicted $\Delta S_{\max }$ for each event when using (8) from Drushka et al. (2016) (D'16) with $\bar{U}$ and $U_{\max }$, respectively. (b) $\Delta S_{\max }$ versus the total amount of rainfall $R_{\text {tot }}$ for the observed rain events.

A short, bursty rain event like rain events II and III is expected to be spatially inhomogeneous (Wijesekera et al., 1999). Although the ship was generally following the ASIP, Figure 1 shows that during the third rain event they were over $1 \mathrm{~km}$ apart. This could imply that the rain rate measured at the ship was not quite as intense at the location of the ASIP. Also, as the profiler was measuring only 3 times per hour, the actual maximum $\Delta S_{\max }$ could have occurred in between two profiles. On the other hand, the peak value of the rain rate $R_{\max }$ may not be the right metric to describe rain events of short duration, as it is highly dependent on the resolution of the meteorological data. Peak rates observed here hardly lasted longer than 2 min; only after time-averaging does the rain rate approximate a Gaussian distribution like the rain forcing used in Drushka et al. (2016). Averaging the time series of $R$ with different moving average windows strongly reduces $R_{\max }$ but hardly affects the total amount of rain per event, $R_{\text {tot }}$. Figure $7 \mathrm{~b}$ shows an improved correlation for $\Delta S_{\max }$ as a function of $R_{\text {tot }}$. Although the sparsity of observations does not allow for an accurate determination of an empirical relationship, $\Delta S_{\max }$ is positively correlated with $R_{\text {tot }}$ and inversely correlated with the mean wind speed.

The prognostic model in Bellenger et al. (2017) was used to simulate salinity and temperature of the ocean skin layer, and at subskin level. Given the observed air-sea fluxes and a bulk seawater temperature and salinity from ASIP (at 5-m depth), the scheme was implemented with a 2-min timestamp. A similar comparison is made between $\Delta S_{\max }$ resulting from this model, computed as the maximum difference between $S_{5 m}$ and the subskin level $S_{0-}$, and the observed value for each rain event (see Figure 7). The difference between the modeled and observed $\Delta S_{\max }$ is -0.2 psu for rain event III, and 0.08 psu for rain event IV, but insignificant for the other rain events. The complete time series of the modeled $S_{0-}, S_{\text {skin }}, T_{0-}$, and $T_{\text {skin }}$ at 2-min temporal resolution is shown in Figure 8, and is compared to subskin measurement by ASIP (mean over upper $1 \mathrm{~cm}$ ). The model predicts $S_{0-}$ with a total root-mean-square difference of $0.05 \mathrm{psu}$, increasing up to 0.09 psu during rain only (evaluated at the times of an ASIP profile). The modeled $S_{0-}$ suggests that rain event III caused a $\Delta S_{\max }$ higher than was observed with the ASIP. However, line markers indicating the timing of ASIP profiles show that the peak salinity anomaly occurred during the period between two profiles, which forms an explanation for the discrepency between observed and modeled $\Delta S_{\max }$ during rain event III.

The root-mean-square difference of $T_{0-}$ is $0.02^{\circ} \mathrm{C}$, increasing up to $0.03^{\circ} \mathrm{C}$ during rain. For rain events II and IV, the rain-induced cooling is slightly underestimated, which is a known feature of the model in moderate and high wind speed conditions.

Under norain conditions the ocean surface microlayer with a thickness of $O(1 \mathrm{~mm})$ is typically more salty and cooler than the water below it (e.g., Saunders, 1967). However, during rain this cool and haline "skin" 

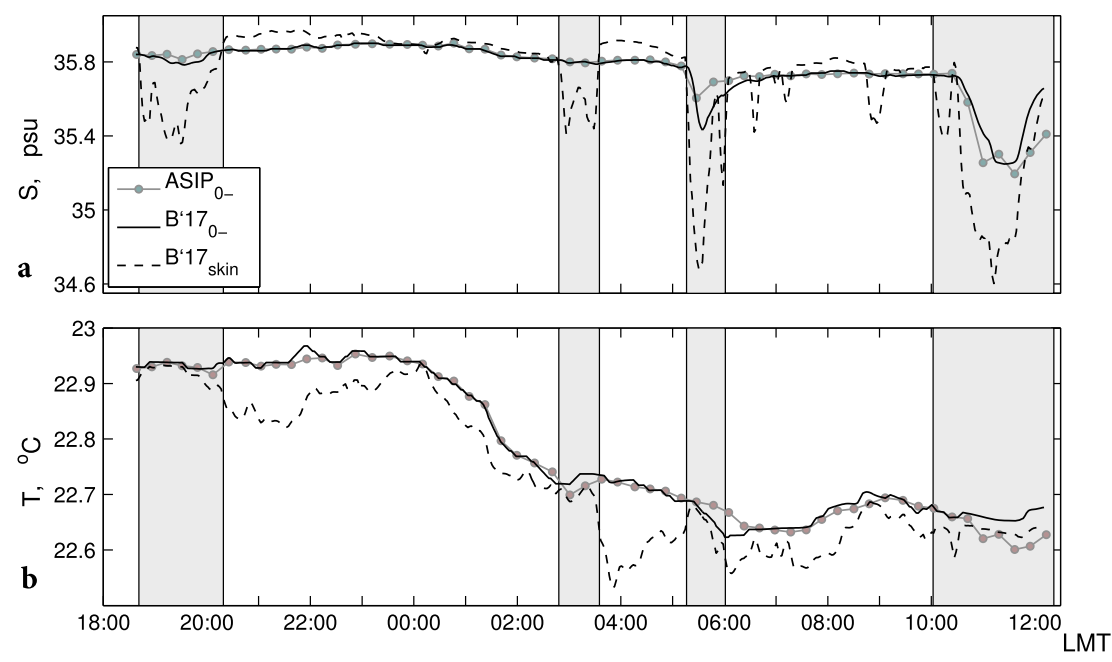

Figure 8. Output of the prognostic model by Bellenger et al. (2017) (B'17) showing salinity $S$ (a) and temperature $T$ (b) of the skin layer and at subskin level (subscript 0-). Gray dotted line shows $S_{0.01 m}$ measured by the Air-Sea Interaction Profiler for comparison.

disappears (Schlüssel et al., 1997). As only the fraction of the raindrops with a large enough drop radius will break through the surface, part of the total freshening is located at the ocean interface. Figure 8 illustrates the significant skin-freshening effect of the precipitation. The output from the prognostic model suggests that the rain-induced salinity anomaly of the surface microlayer was $0.4-0.8 \mathrm{psu}$.

\subsubsection{Comparison to Satellite-Derived Relationship}

To compare the observations to the linear relationships between rain rate and maximum salinity anomaly, the high-resolution time series of $R$ have to be transferred to a scale comparable to the resolution of the various satellite microwave radiometers $(\geq 20 \mathrm{~km})$. The rainfall product from the SSM/I and SSMIS (Special Sensor Microwave Imager, see www.remss.com) has a spatial resolution of $0.25^{\circ}$, approximately $25 \times 25 \mathrm{~km}$ in midlatitudes.

Assuming that the rain travels at approximately the mean wind speed (see Table 1), an event of an hour's duration has a lateral extent on the order of the satellite footprint. Therefore, the time series of rain rate are

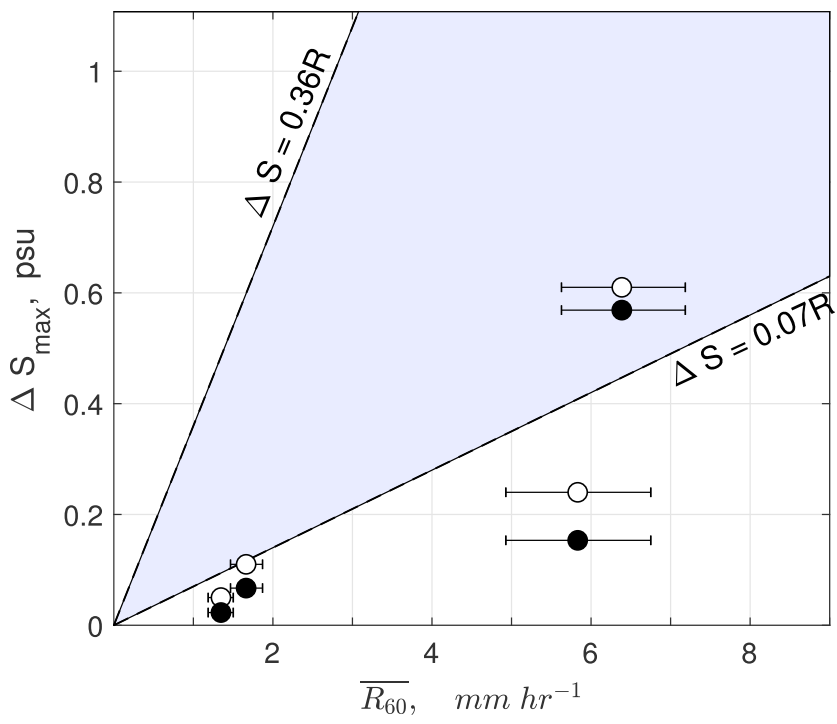

Figure 9. Comparison of the observed maximum salinity difference over the upper $5 \mathrm{~m}$ as a function of the mean 60-min averaged rain rate $\overline{R_{60}}$, to the linear relationships derived from satellite data described in Boutin (2016). The error bars indicate the $95 \%$ confidence interval in $\overline{R_{60}}$ using a bootstrap method. White dots represent $\Delta S_{\max }$ when adding $10 \%$ of the modeled skin layer $\Delta S$. 
averaged using a moving average with a 61-min window; this conserves the total rain amount of each rain event, but reduces the peaks. Then the arithmetic mean of this $R_{60}$ for each rain event is computed, and used as input to equation (7). Figure 9 shows the observed $\Delta S_{\max }$ over the upper $5 \mathrm{~m}$ versus the $\overline{R_{60}}$ for each rain event. The shaded area represents the range of $\Delta S$ calculated with equation (7) for the $c$ values listed in Boutin (2016).

Only one of the observed rain events (IV) falls into the area of the satellite-derived relationships, for the other three $\Delta S$ is overestimated. However, when comparing satellite to in situ salinity, the freshening of the surface microlayer becomes of importance, which was shown to be significant in Figure 8. The sampling depth of a satellite mounted L-band radiometer is approximately $10 \mathrm{~mm}$, while the surface measurement of the ASIP is an average over the upper $2-5 \mathrm{~cm}$. A satellite will therefore capture more of the freshening in the surface microlayer, with a thickness of $O(1 \mathrm{~mm})$, than the ASIP. Adding $10 \%$ of the skin layer freshening from the output of the prognostic scheme by Bellenger et al. (2017) to the $\Delta S$ from ASIP, brings the observed $\Delta S$ for rain events I, II, and III only a little closer to the lower end of the range predicted by equation (7).

\section{Conclusions and Discussion}

Four rainfall events were encountered during an air-sea flux campaign in a midlatitude region of the North Atlantic. Although the cruise was not specifically targeting rain, the combination of vertical profiles of $\epsilon$ and fine structure $T$ and $S$ in the upper ocean from the free-rising vertical profiler ASIP, high-quality meteorology, and air-sea flux observations proved useful to study the upper ocean response to rainfall in this region.

Differences in the atmospheric forcing during the rain events led to a disparate ocean response. Dilution of the surface salinity by rainfall left a clear signature in the $T-S$ curves during three of the four rain events. Rain over the ocean predominantly has an impact if it creates a stably stratified layer below the ocean surface with a lower density than the original surface water. Such freshwater lenses are observed to have formed during each of the four rain events, albeit being weak and short-lived for rain events I-III. During rain event IV the freshwater remained more confined in a shallow layer below the surface, for a longer period of time.

Several explanations can be given for the observed differences in ocean response to rain. Although the four rain events occurred in the same area and within the same 24-hr period, the weather conditions were observed to strongly covary with the rainfall. Bursts in the wind speed and the advection of air masses of different temperatures were changing the local air-sea fluxes of momentum and buoyancy, the balance of which determined the formation and properties of the salinity anomalies. The first two rain events carried a relatively small quantity of freshwater, not contributing to a strong enough buoyancy flux to suppress the wind-driven turbulent mixing. Peaks in the wind following the tail of rain event I, and during rain event II, caused the small salinity stratification observed with ASIP to rapidly disappear. The cooling effect of rain during rain event II may have contributed to this as well, but was of little importance to the surface buoyancy flux $B_{0}$ during the other rain events.

Rain event III was squall-like, which implies that alongside the stronger stabilizing buoyancy flux as a result of the high rain rate, there was an increase in the momentum flux and turbulent kinetic energy available to vertically disperse the freshwater. The fresh anomaly induced by this rain event was therefore small, but observable in the upper $10 \mathrm{~m}$. During rain event IV, on the other hand, wind and wave forcing were temporarily reduced, which confined the salinity anomaly to the upper $3 \mathrm{~m}$ for several hours. The salinity reduction of nearly $0.6 \mathrm{psu}$ is comparable to salinity anomalies observed in tropical regions (e.g., Asher et al., 2014; Drushka et al., 2014; Riser et al., 2015; Soloviev \& Schlüssel, 1996).

Another explanation for the larger salinity anomaly formed during rain event IV is that, although the peak rain rate $R_{\max }$ in rain event III was the largest, the total freshwater input was larger in rain event IV, as this event was of the longest duration.

The presence of freshwater lenses is thought to modulate both the turbulent mixing within it as well as the properties of the remnant mixed layer below. Similarity scaling indicates that during nonrainy conditions the turbulent mixing in the near-surface layer of the study area was mainly wind driven. However, for periods during rain events I, III, and IV the rain-induced stratification suppressed the turbulence. Increased $\epsilon$ above the rain-induced halocline formed in rain event IV indicates that the surface TKE flux was concentrated 
into the shallow fresh layer and that air-sea exchange was limited to this depth. Under this freshwater lens the turbulence intensity was reduced by 2 orders of magnitude.

Unfortunately, the deployment of the ASIP was stopped before the freshwater lens formed by rain event IV had dissipated, so it was not possible to determine its total duration. Drushka et al. (2016) have simulated this specific freshwater lens with the GOTM model, finding that a sea surface salinity anomaly could have persisted for at least $6 \mathrm{hr}$. The air-sea exchange between the surface and the mixed layer would thus have been limited for a significant part of the day.

To study rain effects in open-ocean conditions is challenging, as many of the boundary conditions, which can be fixed in a laboratory environment, cannot be controlled and are often unknown. In relating rainfall rate to salinity anomalies with ocean models, the strongly variable nature of rain is often ignored. Associated wind squalls and changes in air temperature can be large and of direct importance to the mixing conditions (Wijesekera et al., 2005). The observational time series has shown evidence of the occurrence of downdrafts of colder air, reducing the air temperature at sea level, and causing wind gusts before and during the rainfall. Such short timescale features are difficult to account for in models.

The representation of the observed rain-induced salinity anomalies by three models of increasing complexity has been evaluated. The linear functions in Boutin (2016), relating vertical salinity anomalies to rain rate only, are designed to estimate the magnitude of the fresh bias in satellite measured salinity caused by rain in tropical areas. The observed series of rain events in a midlatitude region were relatively small and coincided with changes in atmospheric forcing of direct effect to the ocean surface. A one-parameter function cannot account for this complex forcing and, therefore, overestimates the salinity anomalies.

Incorporation of wind speed is a logical improvement to the parameterization. Nevertheless, the observed salinity anomalies are still overestimated when using the relation between rain rate, wind speed, and salinity anomaly by Drushka et al. (2016), especially for rain event III. The relation in equation (8) was determined from sensitivity tests of $R_{\max }$ and $\bar{U}$ versus $\Delta S_{\max }$, using a constant $\bar{U}$ and a Gaussian-shaped rain rate. When instead of $\bar{U}$ the maximum wind speed during the rain event $U_{\max }$ is used in equation (8), forming an upper limit to the wind-induced vertical mixing, the results only marginally improve. Our observations suggest that for short bursts of rain, typical of atmospheric cold fronts in midlatitudes, the peak rain rate $R_{\max }$ is not the most appropriate characteristic to predict the surface salinity anomaly, since $R_{\max }$ is dependent on the resolution of the time series used. Averaging the time series of rain over a certain period, or area, causes a reduction of $R_{\max }$, while affecting less the total rain rate $R_{\text {tot }}$. After forcing GOTM with a fixed $R_{\text {tot }}$ for variable $R_{\max }$, Drushka et al. (2016) concluded that the first metric is positively correlated to the duration of a freshwater lens, while the second controls $\Delta S_{\max }$. However, the time series here of rain rate in each rain event strongly deviated from a Gaussian relationship. Regression of the observed $\Delta S_{\max }$ versus $R_{\text {tot }}$ (Figure 7b) supports the hypothesis that $R_{\text {tot }}$ is a more robust parameter from which to estimate $\Delta S_{\max }$. The large variability between the rain events here makes it difficult to draw firm conclusions on the effect of rain stratifying the upper ocean from such a small experiment. It is therefore suggested that more extensive observational records of rain-induced salinity anomalies be used to determine a parameterization based on integrated rain rate and momentum flux to facilitate comparison of data sets of different temporal resolution.

It comes as no surprise that the representation of the observed $\Delta S_{\max }$ is better when instead of mean forcing parameters, the evolution of the surface and near-surface salinity is modeled with a numerical model directly. The Zeng et al. (2005) model was designed to compute accurate sea surface temperature values for use in numerical weather prediction and climate models. Adapted by Bellenger et al. (2017) to include the effect of rain, the prognostic model has proven well capable to simulate the observations of subsurface $S$ and $T$, while providing interesting information of the magnitude of the rain-induced freshening and cooling over the ocean skin layer. The use of the bulk air-sea heat and momentum fluxes at high temporal resolution has resulted in a detailed time series of subsurface $S$ (and $T$ ). It illustrates the short timescales on which fresh lenses develop, and that the profiling frequency of the ASIP has not been high enough to capture the maximum salinity anomaly during each of the rain events.

The rainfall measurements from the regular weather systems on ships provide "bucket-measures" of rainfall rate. They do not give information about the size distribution and impact velocity of the rain, and measured rain rates may be affected by the motion of the ship (Klepp, 2015). The terminal velocity and penetration depth of rain drops are dependent on the dropsize distribution. Small drops add freshwater to the surface 
skin layer, whereas larger droplets can penetrate to tens of centimeters depth, forming a volume source instead (Peirson et al., 2013; Schlüssel et al., 1997). Models like the prognostic scheme from Bellenger et al. (2017) use parameterizations to account for these effects, but the natural variability of them has seldom been measured in oceanic field studies. The impact of the raindrops may contribute to enhanced turbulence in the freshwater lens as well. Zappa et al. (2009) observed that the velocity fluctuations caused by falling raindrops can induce turbulence with a dissipation rate of $O\left(10^{-3}\right) \mathrm{W} / \mathrm{kg}$ in the upper $5-10 \mathrm{~cm}$ of the water column. Harrison and Veron (2017) measured $\epsilon$ under rain of order $O\left(1.5 \times 10^{-5}\right) \mathrm{W} / \mathrm{kg}$ in the upper centimeters, decaying as a function of $z^{-5 / 3}$. The ASIP profiles do not have the resolution to validate these measurements in the open ocean, as the most shallow estimate of $\epsilon$ is determined from spectra computed over a data segment of approximately $50-\mathrm{cm}$ depth. The observed $\epsilon$ thus reflects mean dissipation rate over this layer.

This study has shown that the formation of stable freshwater lenses at the ocean surface due to rain is not a phenomenon of tropical regions only. The ASIP has proven suitable of the observation of these. Since the profiler is semi-Lagrangian, it is likely that repeated profiles will approximately measure the same volume of water, allowing for the observation of the vertical evolution of a rain-induced freshwater lens, as well as the ambient vertical mixing. This is at the same time the largest limitation of this study, as we have no information about the horizontal extent of the freshwater anomalies. Along its path the ASIP encountered some variability in the $T$-S properties of the layer below the surface mixed layer and velocity measurements in the mixed layer show that horizontal currents were present and variable here. It is thus likely that horizontal processes were playing a role in the evolution of surface anomalies in this specific study region, located just north of the mean path of the Gulf Stream. Soloviev et al. (2015) showed the edge effects in the presence of horizontal advection can be of major influence to a fresh water lens. Linear relationships between salinity anomaly, rain rate, and wind speed, like those determined here, as well as Boutin et al. (2013) and Drushka et al. (2016), are unlikely to make accurate predictions of $\Delta S$ in the presence of advection.

Acknowledgments

Funding for this research was provided by the Office of Naval Research under awards N62909-12-1-7064 and N62909-14-1-N296 and Science Foundation Ireland award 16/TIDA/3916. Additional funding was provided by the Norwegian Research Council under projects 233901 and 244262. Travel grants were provided by the Ryan Institute at NUI Galway. We also thank the captains and crew of the R/V Knorr. Data can be accessed at https://doi.org/10.17882/59035.

\section{References}

Anderson, J. E., \& Riser, S. C. (2014). Near-surface variability of temperature and salinity in the near-tropical ocean: Observations from profiling floats. Journal of Geophysical Research: Oceans, 119, 7433-7448. https://doi.org/10.1002/2014JC010112

Asher, W., Jessup, A., Branch, R., \& Clark, D. (2014). Observations of rain-induced near-surface salinity anomalies. Journal of Geophysical Research: Oceans, 119, 5483-5500. https://doi.org/10.1002/2014JC009954

Bao, S., Raman, S., \& Xie, L. (2003). Numerical simulation of the response of the ocean surface layer to precipitation. Pure and Applied Geophysics, 160, 2419-2446.

Bell, T., Bruyn, W. D., Miller, S., Ward, B., Christensen, K., \& Saltzman, E. (2013). Air-sea dimethylsulfide (DMS) gas transfer in the North Atlantic: Evidence for limited interfacial gas exchange at high wind speed. Atmospheric Chemistry and Physics, 13, 11,073-11,087. https:// doi.org/10.5194/acp-13-11073-2013

Bell, T. G., Landwehr, S., Miller, S. D., de Bruyn, W. J., Callaghan, A. H., Scanlon, B., et al. (2017). Estimation of bubbled-mediated air-sea gas exchange from concurrent DMS and $\mathrm{CO}_{2}$ transfer velocities at intermediate-high wind speeds. Atmospheric Chemistry and Physics, 17, 9019-9033. https://doi.org/10.5194/acp-17-9019-2017

Bellenger, H., Drushka, K., Asher, W., Reverdin, G., Katsumata, M., \& Watanebe, M. (2017). Extension of the prognostic model of sea surface temperature to rain-induced cool and fresh lenses. Journal of Geophysical Research: Oceans, 122, 484-507. https://doi.org/10. 1002/2016JC012429

Boutin, J., Chao, Y., Asher, W. E., Delcroix, T., Drucker, R., Drushka, K., et al. (2016). Satellite and In Situ Salinity: Understanding Near-Surface Stratification and Subfootprint Variability. Bulletin of the American Meteorological Society, 97(8), 1391-1407. https://doi. org/10.1175/BAMS-D-15-00032.1

Boutin, J., Martin, N., Reverdin, G., Morisset, S., Yin, X., Centurioni, L., \& Reul, N. (2014). Sea surface salinity under rain cells: SMOS satellite and in situ drifters observations. Journal of Geophysical Research: Oceans, 119, 5533-5545. https://doi.org/10.1002/2014JC010070

Boutin, J., Martin, N., Reverdin, G., Yin, X., \& Gaillard, F. (2013). Sea surface freshening inferred from SMOS and ARGO salinity: Impact of rain. Ocean Science, 9, 183-192. https://doi.org/10.5194/os-9-183-2013

Brainerd, K., \& Gregg, M. (1993). Diurnal restratification and turbulence in the oceanic surface mixed layer 1. Observations. Journal of Geophysical Research, 98, 22,645-22,656.

Brainerd, K. E., \& Gregg, M. C. (1997). Turbulence and stratification on the tropical ocean-global atmosphere-coupled ocean-atmosphere response experiment microstructure pilot cruise. Journal of Geophysical Research, 102(C5), 10,437-10,455. https://doi.org/10.1029/ 96JC03864

Burchard, H., Bolding, K., \& Ruiz-Villarreal, M. (1999). GOTM, A general ocean turbulence model. Theory, implementation and test cases. Italy: European Commission. EUR 18745.

Caldwell, D., \& Elliott, W. P. (1971). Surface stresses produced by rainfall. Journal of Physical Oceanography, 1, $145-148$.

Callaghan, A. H., Ward, B., \& Vialard, J. (2014). Influence of surface forcing on near-surface and mixing layer turbulence in the tropical Indian Ocean. Deep Sea Research I, 94, 107-123. https://doi.org/10.1016/j.dsr.2014.08.009

Cavaleri, L., Bertotti, L., \& Bidlot, J.-R. (2015). Waving in the rain. Journal of Geophysical Research: Ocean, 120, 3248-3260. https://doi.org/ 10.1002/2014JC010348

Christensen, K., Rohrs, J., Ward, B., Fer, I., Brostrom, G., Saetra, O., \& Breivik, O. (2013). Surface wave measurements using a ship-mounted ultrasonic altimeter. Methods in Oceanography, 6, 1-15. https://doi.org/10.1016/j.mio.2013.07.002 
Clayson, C., \& Bogdanoff, A. (2013). The effect of diurnal sea surface temperature warming on climatological air-sea fluxes. Journal of Climate, 26, 2546-2556.

Drucker, R., \& Riser, S. C. (2014). Validation of Aquarius sea surface salinity with ARGO: Analysis of error due to depth of measurement and vertical salinity stratification. Journal of Geophysical Research: Ocean, 119, 4626-4637. https://doi.org/10.1002/2014JC010045

Drushka, K., Asher, W. E., Ward, B., \& Walesby, K. (2016). Understanding the formation and evolution of rain-formed fresh lenses at the ocean surface. Journal of Geophysical Research: Oceans, 121, 2673-2689. https://doi.org/10.1002/2015JC011527

Drushka, K., Gille, S. T., \& Sprintall, J. (2014). The diurnal salinity cycle in the tropics. Journal of Geophysical Research: Oceans, 119, 5874-5890. https://doi.org/10.1002/2014JC009924

Esters, L., Landwehr, S., Sutherland, G., Bell, T. G., Christensen, K. H., Saltzman, E. S., et al. (2017). Parameterizing air-sea gas transfer velocity with dissipation. Journal of Geophysical Research: Oceans, 122, 3041-3056. https://doi.org/10.1002/2016JC012088

Fairall, C., Bradley, E., Hare, J., Grachev, A., \& Edson, J. (2003). Bulk parameterization of air-sea fluxes: Updates and verification for the COARE algorithm. Journal of Climate, 16, 571-591.

Fairall, C., Bradley, E., Rogers, D., Edson, J., \& Young, G. (1996). Bulk-parameterization of air-sea fluxes for tropical ocean global atmosphere coupled-ocean atmosphere response experiment. Journal of Geophysical Research, 101, 3747-3764.

Fore, A. G., Yueh, S. H., Tang, W., Stiles, B. W., \& Hayashi, A. K. (2016). Combined active/passive retrievals of ocean vector wind and sea surface salinity with SMAP. IEEE Transactions on Geoscience and Remote Sensing, 54(12), 7396-7404. https://doi.org/10.1109/TGRS. 2016.2601486

Gosnell, R., Fairall, C., \& Webster, P. (1995). The sensible heat flux of rainfall in the tropical ocean. Journal of Geophysical Research, 100, 18,437-18,442. https://doi.org/10.1029/95JC01833

Harrison, E. L., \& Veron, F. (2017). Near-surface turbulence and buoyancy induced by heavy rainfall. Journal of Fluid Mechanics, 830, 602-630. https://doi.org/10.1017/jfm.2017.602

Harrison, E. L., Veron, F., Ho, D. T., Reid, M. C., Orton, P., \& McGillis, W. R. (2012). Nonlinear interaction between rain- and wind-induced air-water gas exchange. Journal of Geophysical Research, 117, C03034. https://doi.org/10.1029/2011JC007693

Karstensen, J., \& Lorbacher, K. (2011). A practical indicator for surface ocean heat and freshwater buoyancy fluxes and its application to the NCEP reanalysis data. Tellus A, 63(2), 338-347. https://doi.org/10.1111/j.1600-0870.2011.00510.x

Katsaros, K., \& Buettner, K. (1969). Influence of rainfall on temperature and salinity of the ocean surface. Journal of Applied Meteorology, $8,15-18$.

Klepp, C. (2015). The oceanic shipboard precipitation measurement network for surface validation-OceanRAIN. Atmospheric Research, 163, 74-90. https://doi.org/10.1016/j.atmosres.2014.12.014, 6th Workshop of the International Precipitation Working Group.

Lagerloef, G. (2012). Satellite mission monitors ocean surface salinity. Eos, Transactions American Geophysical Union, 93(25), 233-234. https://doi.org/10.1029/2012EO250001

Landwehr, S., O'Sullivan, N., \& Ward, B. (2015). Direct flux measurements from mobile platforms at sea: Motion and airflow distortion corrections revisited. Journal of Atmospheric and Oceanic Technology, 32(6), 1163-1178. https://doi.org/10.1175/JTECH-D-14-00137.1

Large, W. G., McWilliams, J. C., \& Doney, S. C. (1994). Oceanic vertical mixing: A review and a model with a nonlocal boundary layer parameterization. Reviews of Geophysics, 32(4), 363-403. https://doi.org/10.1029/94RG01872

Liu, X., Zheng, Q., Liu, R., Sletten, M. A., \& Duncan, J. H. (2017). A model of radar backscatter of rain-generated stalks on the ocean surface. IEEE Transactions on Geoscience and Remote Sensing, 55(2), 767-776. https://doi.org/10.1109/TGRS.2016.2614897

Lombardo, C., \& Gregg, M. (1989). Similarity scaling of viscous and thermal dissipation in a convective surface boundary layer. Journal of Geophysical Research, 94, 6273-6284.

Lueck, R. (2016). RSI TN 028: Calculating the rate of dissipation of turbulent kinetic energy. Victoria BC, Canada: Rockland Scientific International Inc.

Macoun, P., \& Lueck, R. (2004). Modeling the spatial response of the airfoil shear probe using different sized probes. Journal of Atmospheric and Oceanic Technology, 21, 284-297.

Marshall, J., \& Palmer, W. M. (1948). The distribution of raindrops with size. Journal of Atmospheric Sciences, 5, $165-166$.

Mecklenburg, S., Drusch, M., Kerr, Y., Font, J., Martin-Neira, M., Delwart, S., et al. (2012). ESA's soil moisture and ocean salinity mission: Mission performance and operations. IEEE Transactions Geoscientific Remote Sensing, 50, 1354-1366. https://doi.org/10.1109/TGRS 2012.2187666

Miller, S., Marandino, C., de Bruyn, W., \& Saltzman, E. S. (2009). Air-sea gas exchange of $\mathrm{CO}_{2}$ and DMS in the North Atlantic by eddy covariance. Geophysical Research Letters, 36, L15816. https://doi.org/10.1029/2009GL038907

Monin, A. S., \& Obukhov, A. M. (1954). Basic laws of turbulent mixing in the surface layer of the atmosphere. Tr. Akad. Nauk SSSR Geophiz Inst, 24, 163-187. adapted by Keith McNaughton (2008) from a translation by John Miller (1959).

Oakey, N. (1982). Determination of the rate of dissipation of turbulent kinetic energy from simultaneous temperature and velocity shear microstructure measurements. Journal of Physical Oceanography, 12, 256-271.

Osborn, T., \& Cox, C. (1972). Oceanic fine structure. Geophysical Fluid Dynamics, 3(1), 321-345. https://doi.org/10.1080/ 03091927208236085

Peirson, W., Beyá, J., Banner, M., Peral, J., \& Azarmsa, S. (2013). Rain-induced attenuation of deep-water waves. Journal of Fluid Mechanics, 724, 5-35. https://doi.org/10.1017/jfm.2013.87

Price, J. (1979). Observations of a rain-formed mixed layer. Journal of Physical Oceanography, 9(3), 643-649. https://doi.org/10.1175/1520-0485(1979)009<0643:OOARFM >2.0.CO;2

Reverdin, G., Morisset, S., Boutin, J., \& Martin, N. (2012). Rain-induced variability of near sea-surface $T$ and $S$ from drifter data. Journal of Geophysical Research, 117, C02032. https://doi.org/10.1029/2011JC007549

Riser, S., Anderson, J., Shcherbina, A., \& D'Asaro, E. (2015). Variability in near-surface salinity from hours to decades in the eastern North Atlantic: The SPURS region. Oceanography, 28, 66-77. https://doi.org/10.5670/oceanog.2015.11

Saunders, P. (1967). The temperature at the ocean-air interface. Journal of the Atmospheric Sciences, 24, $269-273$.

Scanlon, B., Breivik, Ø., Bidlot, J. R., Janssen, P. A. E. M., Callaghan, A. H., \& Ward, B. (2016). Modelling whitecap fraction with a wave model. Journal of Physical Oceanography, 46, 887-894. https://doi.org/10.1175/JPO-D-15-0158.1

Scanlon, B., \& Ward, B. (2016). The influence of environmental parameters on active and maturing oceanic whitecaps. Journal of Geophysical Research: Oceans, 121, 3325-3336. https://doi.org/10.1002/2015JC011230

Schlüssel, P., Soloviev, A., \& Emery, W. (1997). Cool and freshwater skin of the ocean during rainfall. Boundary Layer Meteorology, 82, 437-472.

Schmitt, R. (1995). The ocean component of the global water cycle. Reviews of Geophysics, 33, 1395-1409.

Schmitt, R., Bogden, P. S., \& Dorman, C. E. (1989). Evaporation minus precipitation and density fluxes for the North Atlantic. Journal of Physical Oceanography, 10, 1210-1221. 
Smyth, W. D., Zavialov, P. O., \& Moum, J. N. (1997). Decay of turbulence in the upper ocean following sudden isolation from surface forcing. Journal of Physical Oceanography, 27(5), 810-822. https://doi.org/10.1175/1520-0485(1997)027<0810:DOTITU>2.0.CO;2

Soloviev, A., \& Lukas, R. (2014). The near-surface layer of the ocean, structure, dynamics and applications (2nd ed.). Netherlands: Springer.

Soloviev, A., Lukas, R., Hacker, P., Schoeberlein, H., Baker, M., \& Arjannikov, A. (1999). A near-surface microstructure sensor system used during TOGA COARE. Part II: Turbulence measurements. Journal of Atmospheric and Oceanic Technology, 16(11), 1598-1618. https://doi.org/10.1175/1520-0426(1999)016<1598:ANSMSS>2.0.CO;2

Soloviev, A. V., Matt, S., \& Fujimura, A. (2015). Three-dimensional dynamics of freshwater lenses in the ocean's near-surface layer. Oceanography, 28, 142-149.

Soloviev, A., \& Schlüssel, P. (1996). Evolution of cool skin and direct air-sea gas transfer coefficients during daytime. Boundary-Layer Meteorology, 77, 45-68.

Sutherland, G., Christensen, K., \& Ward, B. (2013). Wave-turbulence scaling in the ocean mixed layer. Ocean Science, 9, 597-608. https:// doi.org/10.5194/os-9-597-2013

Sutherland, G., Marié, L., Reverdin, G., Christensen, K., Broström, G., \& Ward, B. (2016). Enhanced turbulence associated with the diurnal jet in the ocean surface boundary layer. Journal of Physical Oceanography, 46, 3051-3067. https://doi.org/10.1175/JPO-D-15-1072.1

Sutherland, G., Reverdin, G., Marié, L., \& Ward, B. (2014). Mixed and mixing layer depths in the ocean surface boundary layer under conditions of diurnal stratification. Geophysical Research Letters, 41, 8469-8476. https://doi.org/10.1002/2014GL061939

Tsimplis, M. (1992). The effect of rain in calming the sea. Journal of Physical Oceanography, 22, 404-412.

Tsimplis, M., \& Thorpe, S. (1989). Wave damping by rain. Nature, 342, 893-895.

Turk, D., Zappa, C. J., Meinen, C. S., Christian, J. R., Ho, D. T., Dickson, A. G., \& McGillis, W. R. (2010). Rain impacts on $\mathrm{CO}_{2}$ exchange in the western equatorial Pacific Ocean. Geophysical Research Letters, 37, L23610. https://doi.org/10.1029/2010GL045520

Umlauf, L., \& Burchard, H. (2005). Second-order turbulence closure models for geophysical boundary layers. A review of recent work. Continental Shelf Research, 25(7), 795-827. https://doi.org/10.1016/j.csr.2004.08.004

Walesby, K., Vialard, J., Minnett, P., Callaghan, A., \& Ward, B. (2015). Observations indicative of rain-induced double diffusion in the ocean surface boundary layer. Geophysical Research Letters, 42, 3963-3972. https://doi.org/10.1002/2015GL063506

Ward, B., Fristedt, T., Callaghan, A. H., Sutherland, G., Sanchez, X., Vialard, J., \& ten Doeschate, A. (2014). The Air-Sea Interaction Profiler (ASIP): An autonomous upwardly-rising profiler for microstructure measurements in the upper ocean. Journal of Atmospheric and Oceanic Technology, 31, 2246-2267. https://doi.org/10.1175/JTECH-D-14-00010.1

Webster, P., Clayson, C., \& Curry, J. (1996). Clouds, radiation, and the diurnal cycle of sea surface temperature in the tropical western Pacific. Journal of Climate, 9, 1712-1730.

Weller, R., Fisher, A., Rudnick, D., Eriksen, C., Dickey, T., Marra, J., et al. (2002). Moored observations of upper-ocean response to the monsoons in the Arabian Sea during 1994-1995. Deep Sea Research II, II(49), 2195-2230. https://doi.org/10.1016/S0967-0645(02)00035-8

Wijesekera, H., Paulson, C., \& Huyer, A. (1999). The effect of rainfall on the surface layer during a westerly wind burst in the western equatorial Pacific. Journal of Physical Oceanography, 29, 612-632.

Wijesekera, H., Rudnick, D., Paulson, C., Pierce, S., Pegau, W. S., Mickett, J., \& Gregg, M. (2005). Upper ocean heat and freshwater budgets in the eastern Pacific warm pool. Journal of Geophysical Research, 110, C08004. https://doi.org/10.1029/2004JC002511

Zappa, C., Ho, D., McGillis, W., Banner, M., Dacey, J., Bliven, L., et al. (2009). Rain-induced turbulence and air-sea gas transfer. Journal of Geophysical Research, 114, C07009. https://doi.org/10.1029/2008JC005008

Zeng, X., Beljaars, A., \& L14605 (2005). A prognostic scheme of sea surface skin temperature for modeling and data assimilation. Geophysical Research Letters, 32, L14605. https://doi.org/10.1029/2005GL023030 